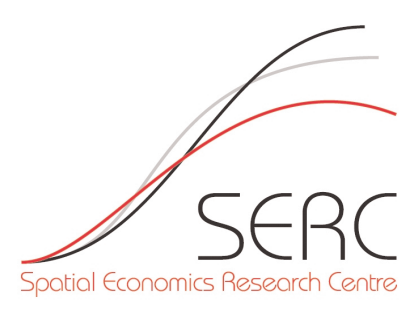

SERC DISCUSSION PAPER 139

Urban Escalators and Inter-regional Elevators:

The Difference that Location, Mobility

and Sectoral Specialisation make to

Occupational Progression

Tony Champion (SERC, CURDS, Newcastle University)

Mike Coombes (SERC, CURDS, Newcastle University)

lan Gordon (SERC, LSE)

September 2013 
This work is part of the research programme of the independent UK Spatial Economics Research Centre funded by a grant from the Economic and Social Research Council (ESRC), Department for Business, Innovation \& Skills (BIS) and the Welsh Government. The support of the funders is acknowledged. The views expressed are those of the authors and do not represent the views of the funders.

(c) T. Champion, M. Coombes and I. Gordon, submitted 2013 


\title{
Urban Escalators and Inter-regional Elevators: The Difference that Location, Mobility and Sectoral Specialisation make to Occupational Progression
}

\author{
Tony Champion* \\ Mike Coombes \\ Ian Gordon
}

\section{September 2013}

* SERC and Centre for Urban and Regional Development Studies (CURDS), Newcastle University

** SERC and Department of Geography and Environment, London School of Economics

\section{Acknowledgements}

Data analyses in this paper are based on micro-data from the Office of National Statistics' (ONS) Longitudinal Study (LS), linking England and Wales Census data for a (roughly) 1\% sample of the population, accessed securely via the Virtual Microdata Laboratory in ONS. Census output is Crown copyright and is reproduced with the permission of the Controller of HMSO and the Queen's Printer for Scotland. The permission of the ONS to use the LS for this study is gratefully acknowledged, as is the substantial help provided by staff of the Centre for Longitudinal Study Information \& User Support (CeLSIUS). CeLSIUS is supported by the ESRC Census of Population Programme (Award Ref: RES 348-25-0004). This presentation has been cleared by ONS (Clearance Number 30112) but the authors alone are responsible for the interpretation of the data. Analysis has been supported by ESRC/BIS/WAG grants to the Spatial Economic Research Centre, but these sponsors also bear no responsibility for findings reported here. 


\begin{abstract}
This paper uses evidence from the (British) Longitudinal Study to examine the influence on occupational advancement of the city-region of residence (an escalator effect) and of relocation between city-regions (an elevator effect). It shows both effects to be substantively important, though less so than the sector of employment. Elevator effects are found to be associated with moves from slacker to tighter regional labour markets. Escalator effects, on the other hand, are linked with residence in larger urban agglomerations, though not specifically London, but also across most of the Greater South East and in second/third order city-regions elsewhere. Sectoral escalator effects are found to be particularly strong in knowledge-intensive activities, with concentrations of these, as of other advanced job types (rather than of graduate labour), contributing strongly to the more dynamic city-regional escalators. The impact of the geographic effects is found to vary substantially with both observed and unobserved personal characteristics, being substantially stronger for the young and for those whose unobserved attributes (e.g. dynamic human capital) generally boost rates of occupational advance.
\end{abstract}

Keywords: Escalator region; labour migration; elevator effect; city-regions; social mobility; career progression

JEL classification: J24; J61; J62; R23 


\section{Introduction}

The 'resurgence of cities' announced around the time of the millennium, in countries which had been early adopters of mass urbanisation but where for some decades it had gone out of fashion, owed much to the sense that in these societies (as well as in the newly urbanising global south) this was where bright young people wanted to live. That enthusiasm may not actually have been new, but over the past 40 years or so the kinds of people who tend to congregate in cities out of choice particularly the unmarried, those with higher education, and/or with cosmopolitan origins - have become very much more numerous. Their preferences for living in, and close to the heart of bigger communities, have several aspects, including (for many) a bias toward urban rather than rural leisure pursuits, and a taste for more tolerant (even Bohemian) communities (as Florida, 2002 argued) - but also a perception that these are the best places in which to 'get on', in career terms.

As a popular belief, this idea has a very long history. As a geographic proposition, however, it seems to have been first advanced by Fielding $(1989,1992)^{1}$ who found from evidence for the 1970s that;

'as an 'escalator' region, the South East attracts .. upwardly-mobile young adults .. socially

promotes them and then encourages their out-migration .. in later middle-age or at .. retirement .. cash(ing) in .. assets .. gained from their passage through the .. region's housing/labour market' $(1993$, p. 158).

In emphasising the regional specificity of this 'escalator', Fielding (1992) relates it to the cultural hegemony within South East England of a modern 'service class' (or salariat), with a cosmopolitan openness to ideas and practices from elsewhere, as against more locally-rooted cultural identities in other regions with stronger agricultural or industrial histories. Alternatively, however, the South East may be seen as synonymous with the London metropolitan economy (Hall, 1989), at the top of a hierarchy of functional urban areas - some others of which might also offer mini-escalators. That would be closer to the perspective of the spatial economists who have come to analyse comparable phenomena elsewhere (if in terms of earnings growth rather than class transitions), as an aspect of agglomeration economies, involving thick / flexible labour markets, as well as high order central place functions (Glaeser and Mare, 2001; Glaeser and Resseger, 2010; de La Roca and Puga, 2012).

Fielding's own analyses had two other recognisably geographic aspects to them. One extended to the national scale (and labour migration) a life-cycle residential model more traditionally applied

\footnotetext{
${ }^{1}$ Though Elias and Blanchflower (1987) had previously highlighted a counterpart in the tendency for young labour market entrants in areas of high unemployment to progress less effectively up the occupational ladder.
} 
within city-regions (for housing/environmentally motivated moves). In the familiar version, young single people are seen as being drawn into inner urban areas offering high accessibility, particularly to work opportunities, but moving outwards in search of affordable space when they formed families, and then ultimately beyond the metro area at the point of retirement when job accessibility ceased to be relevant. In Fielding's longer-distance version, the young - or at least the more ambitious - head for those urban regions where they can get ahead, building an economic position for themselves, which they can take to a comparable role in another region when they have advanced as far as they can on the metropolitan escalator.

The other particular feature in Fielding's (1993) account was an emphasis on the specific economic context of an era (from the 1960s on) in which a new task-based spatial division of labour (Massey, 1984) was intensifying the social class disparities between regions in terms of economic opportunities. Increasingly multi-regional firms were assigning their routine functions to backoffices or branch plants in areas with slacker labour markets, where such jobs could be more cheaply filled, while concentrating strategic, innovative and market-facing work within top tier cityregions (such as London). Ports of entry to higher status jobs in such firms would also have increasingly been concentrated in this region - with some perhaps in second-order provincial centres.

The importance that Fielding $(1989,1992)$ attached to this factor as the basis of the regional escalator he found as operating during the 1970s was borne out by his subsequent observation that all of the dramatic changes of the next decade - which in Greater London reversed an established pattern of population and employment contraction (Buck et al., 2002) - produced no intensification of the escalator process, simply its continuation (Fielding, 1995). Through an era of massive growth in office-related activities, competitive pressures ensured that London essentially hung on to its dominance in those unroutinisable functions which (as we see it) provide the crucial portals to the escalator as well as the career targets at its end.

One aim of this paper is to extend Fielding's work in a number of directions: updating the evidence base on escalator processes to the 1991-2001 decade; examining whether these are relevant only to mobility into the (top) service class, or operate across the whole range of job statuses; and 
applying a more specifically urban lens, to see whether there was evidence of (presumably shorter) escalators operating in some second /third order centres as well as in the London city-region.

Beyond these extensions it also aims to address two new questions. One is about the extent to which it is (simply) a shift of location from elsewhere into one of these escalator regions that brings advancement, or whether (for migrants or natives) this develops over time through an accumulation of experience 'on the escalator'. The other asks whether either process (simply) reflects a concentration of advantageous job types in the favoured regions, or (also) the influence of broader urban externalities. These each seem relevant to the big 'welfare' issue: of whether such escalators make a substantial contribution to the national economy through the creation of new economic assets (in the form of human capital), or just offer privileged access to better careers for a favoured group. They could also have a bearing on the question of why flows of net migration to core regions continue if such flows actually play the equilibrating role conventionally claimed for them (Evans, 1990). In pursuing each of these, we shall pay some particular attention to the (so far neglected) question of what roles specific sectors of employment play in this process, for individuals and/or areas.

\section{Literature: Theory and Existing Evidence}

Versions of this escalator phenomenon have recently been investigated from two perspectives. One strand has involved population geographers, interested in the relationship between spatial and social mobility; essentially in terms of moves across regional and class boundaries, and mostly in a British context (Fielding, 1992, 1993; Findlay et al, 2009; Champion et al., 2013). The other strand has involved spatial economists, interested in dynamic aspects of agglomeration economies within big city labour markets; focusing on geographic variations in rates of earnings growth for individuals, in both North American and continental European contexts (Glaeser and Mare, 2001; Glaeser and Resseger, 2010; de la Roca and Puga , 2012; Newbold and Brown, 2012). Migration does figure in their work, but essentially as a means of separating spatial effects from those of individual attributes (to which the geographic studies paid little attention, even in relation to observable characteristics). Following Fielding, however, geographers have treated mobility - both 
into and subsequently out of the escalator region(s) - as an intrinsic, indeed central, element in the process.

\subsection{Spatial Influences on Labour Market Advancement}

Until Findlay et al (2009) the population geographers actually made no clear distinction between: one-off boosts to occupational position secured simply by relocation from a less to a more advantaged regional context; and the continuing advances which may be achieved (with some effort) in a more dynamic labour market - by established residents (with appropriate qualities) as much as by in-migrants. This distinction has been much more central to spatial economists' studies of earnings change, where one-off effects of migration have been characterised in productivity terms (reflecting spatial disparities in the use made of human capital), while the continuing impacts have been identified with learning effects (involving increments to human capital). This paper applies that distinction to the more specific issue of occupational progression, treated more or less as in Fielding's studies, and retaining his escalator term, but restricting it to the continuing effects of location on (all) resident's economic progress, while labelling the one-off impacts of migration as elevator effects (as in Gordon, $2012^{2}$ ).

Drawing then both on the (Fielding-inspired) work of regional population-geographers and the urban labour market focus of (Glaeser-inspired) spatial economists, our perspective is framed in terms of the potential influence of different city-regional contexts on the prospects of advancement (or retreat) on the occupational ladder. As we see it, these depend on the accumulation (or depletion) of human (and social) capital, with advancement requiring the combination of particular personal capacities/motivations ('dynamic human capital') and access to specific types of job ('opportunities') which offer their occupants a real chance of acquiring marketable assets, in terms of tacit knowledge and connections (Gordon, 2012). Both the distribution of these two factors and the way in which they interact are hypothesised to vary geographically, at the scale of broad city-regions.

\footnotetext{
${ }^{2}$ Our usage of this distinction parallels that of Newbold and Brown (2012), picking up on the continuing upward movement (over time) of those on an escalator, until they 'step off' (Fielding, 1992). It is at odds, however, with the usage of Findlay et al (2009), who see the escalator's distinguishing feature as the horizontal (spatial) movement required to achieve any upward shift.
} 
More specifically, location within one city-region or another is conceived of as affecting an individual's occupational trajectory in four main ways:

(a) as the context for pre-labour market socialisation, potentially affecting both educational achievement and motivation, in more or less positive ways according to community, labour market and family influences;

(b) the richness (or absence) of those local opportunities offering more valuable forms of onthe-job learning, according to the functional/sectoral mix of the local economy, and its agglomeration economies;

(c) the local chances of converting a current set of human assets into employment at a particular status level, given the influence of local labour market tightness/slackness on employers' hiring standards; and

(d) the varying risks of getting 'bumped down' the job ladder (and then losing human capital) as a consequence of the local incidence of redundancies, in places with differing degrees of dependence on contracting or unstable activities.

Of these, the first and last are seen as shaping relatively durable personal attributes in ways that may not readily be modified by relocation. The second and third, however, could offer strong motives for labour migration, aimed at securing upgrading through, respectively, (continuing) escalator effects or (one-off) elevator effects - or both. Either would be economically functional, in securing more productive use of a current stock of human assets. It is the escalator function, however, that seems (potentially) the more significant, as a path through which agglomeration could contribute both to productivity levels and economic dynamism, by enabling a faster and market-directed upgrading of skill stocks.

\subsection{Who Gets Moved Up (or down)?}

The salience of escalator and elevator effects is likely to vary a lot between different population groups, with reasonable grounds for expecting benefits to be concentrated among a minority of younger, better-educated, ambitious and/or more mobile individuals.

Age variations are likely to affect both elevator and escalator effects, though differences in their dynamics should have quite distinct implications for locationally strategies. In the elevator case, a 
one-off occupational advance, from relocation to a stronger region, should generate an increment to earnings that will persist so long as the migrant remains there, and in work. Payoffs for such moves are thus greatest for young workers (cf. Sjaastad, 1962) but, having moved there, migrants would have an incentive to remain until they retire - when (affordable) quality of life considerations may draw them elsewhere.

The (pure) escalator case differs in two or three respects, however:

- what beneficiaries gain from working in the favoured region is an embodied asset that they can take with them to another region;

- the advantage of remaining in the escalator region (despite off-setting factors) rests on the prospect of a continuing enhancement of these assets if they stay; though

- the marginal benefits may substantially diminish over time, either because all the crucial knowledge and connections have been acquired, or because the will and capacity to pursue them fades (with age or shifting priorities).

In this case, it is a slowing in the pace of advancement - as workers move beyond the period of most intense on-job knowledge acquisition - which might justify relocation to a region with fewer learning opportunities, but where accumulated assets could still be deployed, without any necessary loss of status. 'Stepping off the escalator' could thus be expected well before retirement, and in some cases (where the learning period is condensed) after quite a short time in the escalator region. One example would be in those multi-regional organisations where national headquarters (in a core region) provide a fast track for development of people who will later be assigned to leadership roles in their provincially-based operations.

Other personal attributes may also be relevant. In the elevator case - where those seeking a (quick) step up the ladder by moving to a stronger labour market may have to move there speculatively before securing a job - a positive attitude to risk may well be an important sorting factor (Molho, 1986; Williams and Balaz, 2012). In the case of escalator effects, however, what seems crucial is a capacity to effectively exploit informal learning opportunities, using forms of 'dynamic human capital' that encompass both learning skills and motivation. This may well be signalled by success in higher education, but needs to be allied to a level of job-related ambition involving both career goals and intrinsic interest in a line of work (Gordon, 2012). 
Mobility is a necessary aspect of the (inter-regional) elevator process, but has also been seen as a factor enhancing progress up a particular region's escalator. The grounds for this may be just associational, however - because escalator and elevator processes have sometimes been conflated, or because migrants commonly exhibit more of the traits (youth, higher education and lack of attachments) that also favour progress up the escalator, whether or not those concerned have actually made a significant spatial move.

Sector of employment could also be an important (if less remarked) determinant both of rates of occupational advancement and of the strength of escalator processes in major agglomerations. This might have several aspects to it, involving for example the characteristic size structure of businesses or the intensity of market competition in each. But there are also simpler reasons to expect a (positive) link between escalator strength and the dynamism of industries involved, in terms of the incidence of employment growth and of (product, process or institutional) innovation. In both cases the argument would be that these conditions: incentivised employers to encourage workforce development to fill new roles; weakened barriers to upward mobility by talented young recruits; and placed a premium on accumulation of tacit forms of knowledge. These effects could be expected to operate most strongly in the most dynamic places, and in those which housed their most strategically critical functions.

\subsection{Empirical Evidence}

Initial evidence in support of the (pure) escalator hypothesis came from Fielding's (1992) finding that (among non-migrants) upward mobility from working class to professional or managerial jobs during the 1970s was substantially higher in the South East than in any other region of England and Wales. Conflation of blue collar and white collar 'working class' jobs is, however, likely to exaggerate the South East's margin of advantage, since its employment structure would have involved a significantly larger share of workers in white collar roles, with an inherently higher probability of advance to the 'service class'. Indeed, when comparisons are made just in terms of transition rates from white collar jobs, that for people resident in the South East is only $5 \%$ above the national average - and pushed up somewhat by much higher rates among migrants to this 
region $^{3}$ (Fielding, 2007). Fielding's central conclusion about the advantage offered by the South East escalator has generally been taken for granted in subsequent work by (British) population geographers, who have focused on secondary aspects, including movements out of the escalator region, and inter-group differentials in progress (both discussed below), rather than on confirming the basic proposition. Comparative analyses of transitions (among non-migrants) from white collar jobs into the service elite do, however, confirm the significant advantage enjoyed by residents of an extended London region, across 3 decades, but especially in the 1990s (Champion et al., 2013).

In the studies by spatial economists, where advance is measured simply in terms of earnings, Glaeser and Mare (2001) provided clear evidence of a (pure) escalator process advantaging metropolitan residents in the US, on the basis of finding larger gains to experience among those with continuing residence in (larger) metro areas ${ }^{4}$ as against those remaining outside. Closer examination of the variation between metro areas showed, however, that the escalator regions were not actually those with larger populations, but those with a higher proportion of graduates (Glaeser and Resegger, 2010) - which are also presumably those with a stronger representation of knowledge-based jobs.

The basic findings were corroborated by De la Roca and Puga's (2012) longitudinal analysis across Spanish cities. This showed not only that time spent in the two leading cities (Madrid and Barcelona) yielded substantially faster growth in earnings (with a more modest gain from experience in the next tier), but that $90 \%$ of this dynamic (escalator) effect was retained after subsequent moves to lower status cities ${ }^{5}$. On the other hand, in a Canadian analysis focused on migrants, Newbold and Brown (2012) found no indication of a differential acceleration in earnings growth (comparing 5 years before and 5 years after a move) for those going to Toronto - the most likely escalator city - as compared with a matched sample going elsewhere. Simple static comparisons did show larger margins of advantage to Toronto migrants when measured after a longer period in the city. But it seems that the typical Toronto migrant must already have been enjoying above average growth before they moved, implying a form of selection not controlled for

\footnotetext{
${ }^{3}$ The actual transition rates (from white collar working class jobs to the service class) between 1971 and 1981 are $19.7 \%$ versus $18.8 \%$ for all residents of the South East/ England and Wales, and $35.8 \%$ versus $31.1 \%$ for those who had moved between regions (Fielding, 2007, Table 7.3).

${ }^{4}$ with populations over 100 thousand.

${ }^{5}$ in contrast to the (static) elevator effect which was reversed, as would be expected.
} 
by matching on other observed variables. Given quite strong general tendencies for mean reversion in earnings (and occupational status ${ }^{6}$ ), however, it cannot be taken for granted that this trend would have continued unabated, had they moved somewhere else rather than Toronto.

In relation to the elevator process, evidence from population geographers' work on social mobility is more meagre, since (following Fielding, 1992) they have generally not distinguished between static and dynamic components of the status changes recorded for migrants. Findlay et al (2009 are the exception, offering suggestive evidence (from a small sample of employed graduate migrants to the South East) that advances achieved at the time of the move are at least as important as those achieved subsequently. Evidence from spatial economists' studies is much more clear-cut, at least in respect of money earnings, where significant advances are reported for those moving to higher order city-regions (e.g. de la Roca and Puga, 2012; Newbold and Brown, 2012) - if not necessarily in terms of real earnings, as the occupational version of the elevator thesis would imply.

A third area of interest in relation to established empirical findings concerns the issue of how far the benefits of these two processes are concentrated within specific population sub-groups who gain more than others either from residence in, or moving to, favoured city-regions. Despite substantial evidence showing that particular characteristics (including youth, higher educational qualifications and/or mobility) are associated with faster occupational progress, there is very little so far showing how these characteristics interact with the spatial factors. One exception is Gordon (2012) who reports escalator effects among residents of South East England that are dependent on possession of a certain level of job-related ambition. A bit less specifically, de la Roca and Puga (2012) find stronger impacts of their urban escalators among individuals with unobserved attributes favouring higher earnings. Otherwise the one clear finding has been that such benefits are concentrated in the early years of work-experience within the favoured region. In the studies of population geographers the evidence for this is indirect, in terms of observations that British people who had migrated into the South East's escalator region and subsequently 'jumped off' mostly did so before the age of 30 (Findlay et al, 2008; Champion, 2012), rather than waiting until late middle age as Fielding (1992) suggested. In the work of spatial economists the evidence is more direct,

\footnotetext{
${ }^{6}$ See section 4 below and Gordon (2013).
} 
with marginal returns to years of experience approaching zero after 15 years or so ${ }^{7}$ (Glaeser and Resseger, 2010; de la Roca and Puga, 2012). Similarly, a long term analysis of occupational progression (using BHPS data) concluded that 'escalator effects may only really apply while people are in their twenties and early thirties 30s' (Gordon, 2013, 10).

\subsection{Research Questions and Hypotheses}

From this combination of theory and past empirical research, we drew 3 main sets of hypotheses for investigation, namely:

1) that location and relocation can each be expected to exert significant effects on people's chances of accumulating on-job experiences that advance their position up the occupational structure - via distinct escalator and elevator processes, with rather different logics, geographies and implications;

2) more specifically, that:

a. elevator effects, experienced by migrants, should reflect inter-regional variations in the pressure of labour demand (with higher levels of job status being achievable from the same assets in tighter labour markets); while

b. escalator effects, experienced by residents of favoured city-regions, should reflect agglomeration economies and the spatial concentrations of more dynamic industries or high tier occupations (which enable stronger occupational progression); and that

3) both processes have uneven impacts concentrated within some specific population groups:

a. elevator effects being strongest for the young and those in the more dynamic sectors; and

b. escalator effects being strongest among the young, qualified and those with the highest levels of dynamic human capital.

In the analysis that follows these hypotheses are investigated in turn, using information on occupational progression between 1991 and 2001 by residents of English/Welsh city-regions.

\footnotetext{
${ }^{7}$ In the Glaeser-Resseger analysis, the differential effect of residence in a more educated metro area as compared with a non-metro area peaks among those with 16-20 years' experience, while in the Roca-Puga's study their quadratic representation of Madrid-Barcelona experience implies a peak at between 13 and 18 years.
} 


\section{Methods}

\subsection{Data, Sample and Variable Definition}

The data source used for our analyses (as for Fielding's 1971-91 studies) is the Office of National Statistics' Longitudinal Study (LS), linking records for a (roughly) $1 \%$ sample of respondents to successive Population Censuses for England and Wales. Our focus is on change between the 1991 and 2001 Censuses (the latest available for this study), though reference is also made to migration during the previous decade.

The sub-sample used for the analyses is necessarily restricted to those who were present in both Censuses and for whom valid addresses and occupational information were recorded. Additionally we sought to exclude both students and the effectively retired on the basis that their job choices typically to secure cash or 'useful activity' with minimal disturbance to other priorities - were least likely to reflect their occupational capacities. In practice, this meant restricting coverage to people who fell within the working age range at both Censuses and were in employment (and not studying)s at the 1991 Census, irrespective of employment status in 2001, leaving some 145,600 available cases.

The outcome measure of occupational progression is an index of job status (JS) which (following Nickell, 1982) is based on the log earnings of reported occupations (at SOC90 3 digit level), benchmarked for a single period (and a representative region and firm size). Ideally we would have further differentiated 'job niches' in terms of managerial/supervisory responsibilities (as in Gordon, 2013), but this was not possible on a consistent basis between the two Censuses. For our purposes, this measure has three advantages over the traditional focus (by Fielding and followers) on specific class transitions. It covers a much larger proportion of the job moves involving significant changes in status and in required capabilities, though still missing promotions within an occupational category $^{8}$. It avoids prejudgements about which moves are significant and which represent advancement, by working from market evaluations that reflect (most) relevant supply and demand factors. And, because this scale can be directly translated into expected earnings differentials, it offers some indication of the practical importance of an escalator effect for those involved. The JS measure differs, however, from direct use of individual earnings as an outcome indicator (by

\footnotetext{
${ }^{8}$ Such as that of 'university and polytechnic teaching professionals' !
} 
Glaeser and followers), because of a concern to assess and understand how recognised work capabilities develop (and get eroded) in different contexts, as distinct from how their monetary valuation varies between places and over time.

In our analyses, individuals' JS changes over the decade are regressed on a set of other Censusbased indicators, including personal characteristics, spatial location/relocation measures (to identify any escalator/elevator effects), and industrial sectors of employment (to identify advantageous sets of job opportunity). After experiment with a wider range of socio-demographic attributes, the personal characteristics used in the main analyses were restricted to age, gender, possession of a higher (post-18) qualification and employment position (part/full time, and employer/self-employed/employee). Information on more qualitative attributes, such as attitudes, commitment and connectedness, was beyond the scope of the Census data-base - but the combined effect of such unobserved factors was examined via quantile regression (see section 3.3 below)

As an approximation to distinct spatial labour markets, the geographic frame adopted for this analysis was a set of 38 CURDS City-regions (CRs), covering the whole country (Coombes, 2002) ${ }^{9}$. Their scale in population terms varies greatly - between about 0.25 and 12 million - but by design (from 1991 Census commuting flow analyses) they are much more comparable in terms of closure averaging around $81 \%$ on an index taking account of both in-and out-flows ${ }^{10}$. This standard classification was supplemented by measures for 20 'consolidated CRs' (CCRs), including polycentric groupings of more closely linked CRs in urbanised regions ${ }^{11}$.

To minimise problems of endogeneity, independent variables were generally defined in terms of 1991 positions and values. In order to separate pure 'escalator' effects (operating continuously during residence in an area region) from 'elevator' effects (arising on a one-off basis from migration between areas), however, individuals' locations (and industries) in both 1991 and 2001 were considered, using forms of semi-dummy explained below.

\footnotetext{
${ }^{9}$ With boundaries shown in Figure A1 of the statistical appendix.

${ }^{10}$ Closure is measured on the basis of both: $\mathbf{O}$, out-commuters as a proportion of employed local residents; and $\mathbf{I}$, incommuters as a proportion of local jobs. The measure used is: $\mathbf{1}-\left(\mathbf{I}+\mathbf{0}-\mathbf{I}^{*} \mathbf{0}\right)$.

${ }^{11}$ As listed in Table $\mathrm{A} 1$ of the statistical appendix..
} 


\subsection{Methods and Analytic Issues}

A three stage approach was adopted for the analyses, addressing in turn each of the hypothesis sets from section 2.4 (above). In the first, the influence and pattern of geographic and sectoral variables were identified descriptively through inclusion of arrays of (semi-)dummy variables for each sector and area in the JS change regressions. In the second stage, these were then examined in more causal terms, in relation to our hypotheses, using substantive measures of area and industry attributes. The final stage examined interaction effects to assess how far geographic influences on progression were concentrated on a minority sub-set of workers.

\section{Stage 1:}

In this stage, the individual level regression analyses were used to derive area- and industry-specific estimates of location (escalator), relocation (elevator) and sectoral effects on JS change, using three constructed sets of 'semi-dummies' ${ }^{12}$. These variables, derived from combinations of CR or sector dummies for 1991 and 2001, each take 1 of 3 possible values ( 2 extremes and a mid-point).

One set, approximating the proportion of the inter-Censal period through which an individual is exposed to the context of a particular CR (or industry), takes the value 1 for people found there in both Censuses, 0.5 for those present in just one, and zero for those who were elsewhere in both ${ }^{13}$. Coefficients on these provide estimates of sectoral effects (in the industry case) and of escalator effects (in the area case). The other set of semi-dummies, used only for CRs, picks up the (immediate) effect of a locational shift. It takes the value -1 for a person present in the area at the first Census date, but who was elsewhere at the second, +1 for a person present there only at the second date (and elsewhere at the first), or 0 for those who were either there at both dates, or elsewhere on both. Coefficients on these variables provide estimates of the elevator effects.

Underpinning this simple separation of escalator and elevator effects is a pair of assumptions: that escalators have identical effects on migrants and non-migrants (with the same period of exposure to an area); and that elevators operate symmetrically for those moving into and out of a given area

\footnotetext{
${ }^{12}$ As elsewhere (e.g. Marglin, 1987, 453) this term indicates a cardinal variable with some (only) of the attributes of a dummy. Here, more specifically, it involves augmenting a dummy variable by introducing a half-way point.

${ }^{13}$ This approximation ignores the existence of multiple moves within a decade, which mean that some of those treated as continuous residents will have spent part of the decade elsewhere, while those recorded as movers will on average have spent less than $50 \%$ of it in either of the regions where they were enumerated by a Census.
} 
(with gains to one mirroring losses to the other). The first of these assumptions is tested (in stage 3 of the analysis) by comparing escalator effects during this decade for those who did /did not make an inter-CR move in the previous one. The second assumption is not tested here.

This analysis focuses on change over a single ten-year period, but a couple of issues about the dynamics of job mobility need consideration. One of these stems from the fact that (as found with similar data-sets ${ }^{14}$ ) alongside substantial movement between occupations of quite different status levels, a large proportion of the workforce actually remain in the same occupational position. The distribution of JS shifts thus combines two distinct elements, one being effectively normally distributed around a near zero mean, the other adding a sharp spike at zero itself. This spike is likely to reflect a number of factors, including concealed (intra-occupational) status shifts, punctuated equilibria in careers, or real heterogeneity between distinct classes of movers and stayers. In any case it implies some heteroscedasticity in the disturbances - though with the potential for bias being limited both by the proximity of the (stayer) spike to the (mover) mode, and the apparently weak relation between mover/stayer selection and other attributes of interest ${ }^{15}$. For the analyses in this stage, where average effects across the population are of prime interest, this issue has been ignored. Robustness checks undertaken in stage 3 (where quantile analyses focus solely on movers), however, suggest no significant biases for the variables of interest ${ }^{16}$.

The other dynamic issue involves the strong evidence of mean reversion (in this data set as in others ${ }^{17}$ ), in terms of a negative relation between JS change and base year levels. The relation is actually non-linear, with a flattening at both extremes, reflecting a statistical censoring of the extremes of job status (through the graininess of the occupational classification), as well as some effective floor to viable jobs within the formal economy ${ }^{18}$. As we understand it, however, the basic logic is one of (some) 'correction' of discrepancies between ascribed Job Status levels in base year employment, and an individual's sustainable occupational position, given market evaluations of their human capital assets. As such, controlling for this factor is very important for identification

\footnotetext{
${ }^{14}$ Including comparisons over a single year with the Labour Force Survey and over 18 years with the British Household Panel Study (Gordon, 2012).

${ }^{15}$ See section 4, first para., below.

${ }^{16}$ See footnotes 19 and 33 below,

${ }^{17}$ Specifically the shorter and longer term data sets referred to in footnote 12 (Gordon, 2012).

${ }^{18}$ In the mid-range occupations (accounting for two thirds of jobs), the mean reversion factor over the decade was $53 \%$, but over $75 \%$ in the top and bottom deciles.
} 
and measurement of other effects, including those of location and relocation and is handled in our models via a cubic function of base-year JS.

\section{Stage 2:}

In this stage, coefficient estimates for the sectoral, escalator and elevator factors were used as dependent variables in analyses with sets of aggregate indicator variables for sectors or CRs, with the dual aim of: characterising the pattern of each factor; and testing our hypotheses about main causal influences on each. The numbers of observations (and hence degrees of freedom available) was necessarily more restricted at this stage, involving just 52 sectors and 38 CRs.

With a wide range of CR population levels, substantial variation in the reliability of coefficients was likely (and found), leading to the use of weighted least squares for the escalator and elevator equations. These were estimated jointly, in a Seemingly Unrelated Regression framework, to control for some potential displacement of effects between the two spatial factors - though this proved only to be significant for the smaller cases, and unimportant overall when those were down-weighted.

\section{Stage 3:}

Here we return to analysis of the micro-data to examine whether (relatively modest) overall escalator or elevator effects concealed markedly stronger impacts within particular sub-groups. This was addressed in two ways. First, in relation to measured attributes, we added terms for interactions of the spatial and the non-spatial 'factors' (having bundled these into summary measures on the basis of first and second stage analyses). Possible interactions with past migration status were also separately examined at this stage. For those more qualitative influences (including ambition, connectedness and luck/'mojo') not covered by the Census, we used quantile regressions to provide evidence on overall effects of interactions between the spatial variables and such unmeasured factors. This is analogous to de la Roca and Puga's (2012) use of personal effect dummies, in a panel regression (of earnings levels), to investigate interactions between 'ability' and urban status - though with JS change as our dependent variable, the quantiles should reflect more dynamic components of human capital. 
Such quantile analyses are evidently sensitive to the 'spike' effect of a substantial group of job 'stayers' on the error distribution across the full sample, making estimation of the median function in particular quite meaningless. So these were focused entirely on those respondents who recorded some change of (SOC90) occupation between the two Censuses. Potential sample selection bias was then controlled for with a Heckman-like procedure, including both the inverse Mills ratio and its square (derived from a conventional selection equation) as controls in the quantile equations (cf. Buchinsky, 2001; and Bosio, 2009) ${ }^{19}$.

\section{Results}

Even over the decade between the two Censuses, the LS shows that a substantial proportion (38\%) of the selected population group remain in the same occupational category. Among those with some observed change, the JS shift closely followed a normal distribution - with a mean of $+5.2 \%$, and a standard deviation of $36.7 \%{ }^{20}$. What distinguishes the occupational 'stayers' is poorly explained by other recorded attributes. Logit analyses did indicate that they were significantly more likely to: be older; lack higher qualifications; already be in a higher status position (in 1991); be in less dynamic industries (in either year) ${ }^{21}$; and/or live in more peripheral regions. But these accounted for only some $2 \%$ of the differences from those with a recorded occupational change.

Preliminary descriptive analysis of the JS change data confirmed that occupational progression was both age- and education-dependent. Across all of our sample, peak rates of upward mobility were found among those in the youngest age groups (16-19 year old non-students in 1991), declining thereafter and being replaced by net downward shifts from middle age (42 and over in 1991). Typical trajectories differed, however, both by qualification level and by gender. Female progression was notably less in the main child-bearing age range (20-29 in 1991, becoming 30-39 in 2001), but was fairly stable thereafter, only slowing in middle age, and never actually reversed whereas for all males taken together, net downward shifts set in from the late 30s.

\footnotetext{
${ }^{19}$ Robustness of the main (OLS) regression results on the full sample (including stayers) to the non-normal overall error distribution was also assessed at this stage, by comparison with bias-adjusted estimates from the restricted (job mover) sample.

20 The proportionate shift effects referred to in the text of this section simply relate to arithmetic differences in JS values, and coefficient values predicting these. For simplicity, we ignore the fact that this approximation is less accurate for non-marginal shifts, whose effects are somewhat understated at the positive end, and over-stated at the negative one.

${ }^{21}$ as listed in Table $\mathrm{A} 3$ of the statistical appendix..
} 
Overall, those without a higher (18+) qualification, actually showed a more positive trend in JS status over the decade (averaging a 3.4\% gain as compared with 1.5\% for the more qualified). That seems, however, to have been a by-product of a very strong tendency to mean reversion. Among those starting the decade in the bottom quintile there were average gains of $19 \%$, while (in mirror image) those who started in the top quintile tended to fall back, with average losses of $13 \%$ ). After controlling for this apparent regression toward the mean, higher education did emerge as a clearly positive factor, favouring much faster JS progression through the 20 s, and with advances among graduates continuing into the late 40 s.

There were also sharp inter-sectoral differences, particularly in terms of the industries where people were employed in 2001. At one extreme, in finance and IT, there were gains averaging 10$16 \%$ over the decade while, at the other, in retail, land transport and hotels/catering, there were average reductions of $2-6 \%$.

\section{1: Job Status Change Regressions}

In the first stage of the empirical analysis, individuals' progress up the JS scale between 1991 and 2001 was related formally to four groups of variables:

- a set of (1991-based) personal control variables (including age, sex, qualification levels, and initial employment status);

- initial 1991 JS values (represented with a cubic function).;

- the industry semi-dummies (which relate notionally to 1996); and

- the two sets of CR semi-dummies: an escalator set (again relating notionally to 1996), and an elevator set (relating to shifts between 1991 and 2001).

The aims were both to assess the significance of each and to identify the broad patterns of sectoral and spatial variation, as a preliminary to more substantive investigation of these (in the following sub-section)

Summary results are presented in Table 1 for three models. These show firstly (column 1), that quite a substantial proportion (19.6\%) of the individual variation in progress is accounted for by the 
combination of the personal control variables and initial JS values discussed above. Introducing first the city-region variables and then the industry ones (in columns 2 and 3) shows both making significant contributions with little apparent overlap between them, but with the latter clearly being much more powerful (adding about $4 \%$ to the $\mathrm{R}^{2}$ ) than the geographic effects (which contribute only about $0.2 \%$ ). In substantive terms also, a much greater variation is evident in estimated sectoral effects (with a standard deviation of 8\%) than in those associated with either location (the escalator) or relocation (the elevator). On this indicator, the two spatial effects seem of much the same importance (with SDs of $2 \%$ ), though the escalator effects apply to all residents whereas the elevator ones only impinge on migrants, for whom it is the difference between origin and destination region coefficients that matters.

Table 1

Summary of First Stage 1991-2001 Job Status Change Regressions

\begin{tabular}{|l|c|c|c|}
\hline Variable Sets Included & $\mathbf{1}$ & $\mathbf{2}$ & $\mathbf{3}$ \\
\hline Personal Attributes & $\mathrm{x}$ & $\mathrm{x}$ & $\mathrm{x}$ \\
\hline 1991 JS Value & $\mathrm{x}$ & $\mathrm{x}$ & $\mathrm{x}$ \\
\hline $\begin{array}{l}\text { Industry Effects } \\
\begin{array}{l}\text { City-Region } \\
\text { Escalator Effects }\end{array}\end{array}$ & $\mathrm{x}$ & $\mathrm{x}$ \\
\hline \multicolumn{1}{|c|}{ Elevator Effects } &.. & $\mathrm{x}$ & $\mathrm{x}$ \\
\hline $\begin{array}{l}\text { SD of coefficients } \\
\text { industry effects }\end{array}$ &.. & 0.021 & 0.084 \\
\hline escalator effects &.. & 0.022 & 0.020 \\
\hline elevator effects & 145,852 & 145,852 & 0.019 \\
\hline & 0.196 & 0.198 & 0.240 \\
\hline $\mathrm{N}$ & 0.261 & 0.261 & 0.254 \\
\hline $\mathrm{R}^{2}$ & & & 145,852 \\
\hline SE & & & \\
\hline
\end{tabular}

Source: analyses of unpublished 1991/ 2001 Census linked micro-data from ONS Longitudinal Study

Notes: 1. The personal attributes comprised age and log age (both interacted with gender), employment status in 1991 (full/part time employees, self-employed and employers), and possession of a higher (18+) qualification.; 2. Estimated coefficients on these are reported in Table A2 of the statistical appendix.

Across the industrial 'sectors', about a third (20 out of 52) of the estimated coefficients implied significantly above or below average effects on JS progression for those employed in the activity concerned (in one or both Census years) ${ }^{22}$. In each case the difference was substantively

\footnotetext{
22 These sectors are listed in Table A3 of the statistical appendix.
} 
important, with disparities of $18-42 \%$ in JS advances over the decade between the top and bottom 10 sectors. It is notable that activities in the top group include a number of the more knowledgeintensive sectors where employment has tended to grow, while those at the bottom include both declining production sectors and others with many high turnover/low paid 'secondary' type jobs ${ }^{23}$.

Since the latter can be expected to have much lower JS values, it might be suspected that these sectoral 'effects' actually reflect consequences ${ }^{24}$ rather than causes of individuals' progress or regress in human capital terms. This should not be the case, however, since: the dependent variable represents JS change rather than JS levels; and the sectoral semi-dummies give equal weight to where people were employed at the start as well as the end of the decade. Coefficients on these do thus offer prima facie evidence, at least, of sharply varying impacts from time spent in different sectors on rates of human capital accumulation and chances of occupational progression (implying the existence of 'sectoral escalators' operating at quite different speeds ${ }^{25}$ ).

In the case of the two spatial effects, the evidence is admittedly much less striking, and very few individual city-regions show evidence of either escalator or elevator effects differing significantly from the national average ${ }^{26}$. In fact, across the 38 city regions, for the elevator effect there are just two positive cases (Reading and Cambridge) and a single negative one (Hull); while for the escalator effect there are only a pair of positive cases (Reading again and London). The fact that the positive cases all involve leading centres from the Greater South East (GSE) could suggest a common underlying geographical pattern. But across the full set of areas the estimated elevator and escalator coefficients prove quite uncorrelated. Mapping does, however, indicate some spatial patterning for each, with the middle of the country displaying more positive results for the elevator, whereas for the escalator advantage seems to be concentrated within the GSE.

\subsection{Accounting for Sectoral and Spatial Variations in Job Status Change}

\footnotetext{
${ }^{23}$ In these jobs, the 'sectoral' effect estimated, after controlling for mean reversion and youth factors, which should have had quite strongly positive effects, are substantially more negative than the actual (average) JS changes, cited earlier.

${ }^{24}$ In terms of the human capital requirements for gaining admission to jobs in knowledge-intensive sectors.

${ }^{25}$ This is partially reflected in the association (noted above) between less positive sectoral effects and a propensity to remain in the same occupation over the decade.

${ }^{26}$ Shown in Table A4 of the statistical appendix..
} 
The second stage in the empirical analysis involves seeking to translate this evidence of uneven sectoral and spatial effects into intelligible patterns that can be related to our hypotheses and the findings of previous studies. Despite a prime interest in spatial influences, the sectoral dimension is also considered, since how it comes to impact (so strongly) on individuals' chances of progression may have substantial relevance to understanding the area factors, including the salience of local or regional patterns of specialisation. We start therefore by exploring the substantive bases for the profile of inter-sectoral differences emerging from the JS change regressions.

Table 2

Regression of Sectoral Coefficients on Selected Characteristics

\begin{tabular}{|l|c|c|}
\hline & $\mathbf{1}$ & $\mathbf{2}$ \\
\hline Constant & $-.366(8.0)^{* * *}$ & $-.366(9.8)^{* * *}$ \\
\hline Average qualification level & $.104(4.7)^{* * *}$ & $.103(7.2)^{* * *}$ \\
\hline Employment Growth 1991-2001 & $.059(2.6)^{*}$ & $.055(2.5)^{*}$ \\
\hline \% with training in past quarter & $.000(0.3)$ & \\
\hline $\begin{array}{l}\text { \% in firms/estabs with 50+ } \\
\text { workers }\end{array}$ & $.065(1.3)$ & $.013(3.4)^{* *}$ \\
\hline Average years in firm & $.009(1.9)$ & 50 \\
\hline $\mathbf{N}$ & & 0.688 \\
\hline Adjusted $\mathbf{R}^{\mathbf{2}}$ & 50 & .052 \\
\hline SE & 0.686 & .052 \\
\hline
\end{tabular}

Sources: sectoral coefficients from model 3 of the JS change regressions (Table );, establishment size, qualifications and training from Labour Force Surveys for 1996-2000; employment growth from annual employment survey/annual business inquiry (via NOMIS).

Notes : 1. workers' (highest) qualifications are scaled from 5 for a degree to 0 for no qualification; 2. Regressions are weighted in proportion to the square root of numbers employed in each Census; 3 bracketed values are $t$ statistics; asterisks indicate significance $*=5 \%, * *=1 \%, * * *=0.1 \%$.

Among the sectoral characteristics that seem potentially relevant to explain these are: employment growth rates over the decade (as an index of employer need to grow skills); average qualification levels of the workforce (as an indicator both of knowledge/innovation-intensity and worker orientation to learning); the share of jobs in establishments with over 50 workers and employees' average years of service (as indicators of investability from the employer's perspective); and the actual proportion of workers with significant recent training. Exploratory regressions suggested that each of these variables had some relevance, but the strong bivariate relation with training experience disappeared once qualification levels were controlled for (Table 2). This latter factor emerges as the crucial one in distinguishing those sectors which facilitate upward mobility by 
workers, suggesting that the knowledge-intensity of an enterprise (or perhaps of an establishment) strongly conditions the potential for on-the-job learning ${ }^{27}$. But positive employment growth and greater workforce stability (in terms of average job tenures) also appear significant positive factors.

Turning now to the city-region coefficient estimates on escalator and elevator variables, we approach these first descriptively, to see how they relate to key indicators of urban versus regional differentiation, before then investigating more substantive associations with causally relevant variables. For this purpose, three broad regions are distinguished (the GSE 'core', a northern/western 'periphery', and a 'middle England' residual), while urbanity is represented by (logged) population size of the relevant CR/CCR scales, and/or a combined 'agglomeration' index giving equal weight to both ${ }^{28}$.

Table 3

Regressions of Spatial Coefficients on Regional and Agglomeration Indicators

\begin{tabular}{|l|c|c|c|c|}
\hline & \multicolumn{2}{|c|}{1} & \multicolumn{2}{|c|}{2} \\
\hline & Elevator & Escalator & Elevator & Escalator \\
\hline Constant & $\begin{array}{c}-0.0348 \\
(0.9)\end{array}$ & $\begin{array}{c}-0.1166^{* * *} \\
(3.5)\end{array}$ & $\begin{array}{l}0.0060^{*} \\
(2.5)\end{array}$ & $\begin{array}{l}-0.1378^{* * *} \\
(4.8)\end{array}$ \\
\hline North + West Region & $\begin{array}{c}-0.0159 * * \\
(3.1)\end{array}$ & $\begin{array}{c}0.0010 \\
(0.2)\end{array}$ & $\begin{array}{l}-0.0183^{* * *} \\
(4.5)\end{array}$ &.. \\
\hline Greater South East & $\begin{array}{c}0.0002 \\
(0.0)\end{array}$ & $\begin{array}{c}0.0042 \\
(0.9)\end{array}$ &.. &.. \\
\hline CR population (logged) & $\begin{array}{c}0.0002 \\
(0.1)\end{array}$ & $\begin{array}{c}0.0033 \\
(1.6)\end{array}$ &.. & $\begin{array}{l}0.0034 \\
(1.8)\end{array}$ \\
\hline CCR population (logged) & $\begin{array}{c}0.0025 \\
(1.1)\end{array}$ & $\begin{array}{c}0.0049 * * \\
(2.6)\end{array}$ &.. & $\begin{array}{l}0.0063^{* * *} \\
(4.3)\end{array}$ \\
\hline $\mathbf{R}^{2}$ & 0.371 & 0.406 & 0.336 & 0.392 \\
\hline $\mathbf{N}$ & \multicolumn{3}{|c|}{38} & \multicolumn{2}{c|}{38} \\
\hline Correlation of residuals & \multicolumn{3}{|c|}{-0.258} \\
\hline
\end{tabular}

Source: elevator and escalator effect estimates from regression 3 of Table 1

Notes: 1 , Observations are city-regions; 2 . pairs of escalator and elevator equations were estimated jointly using Seemingly Unrelated Least Squares

\footnotetext{
${ }^{27}$ The full range of qualification levels appears to be relevant, not simply the proportion of graduates - indeed when the latter is added as a separate variable it attracts a negative coefficient

${ }^{28}$ In effect this adds to the city-region's own population base half of that in (any) other areas within the CCR).
} 
Consistent with our hypotheses (in section 2), the results of this exercise (as reported in Table 3) highlighted a clear regional variation in values on the elevator factor (being significantly lower, by about $2 \%$, in the periphery, though little different in the other two super-regions) and a significant association between escalator coefficients and agglomeration, with no systematic regional variation. An important finding from examination of kernel plots/regressions ${ }^{29}$ was that this latter relation did not simply (or even primarily) depend on the strength of the London CR's escalator. Indeed for the combined CR/CCR agglomeration index, the relation between escalator values and logged population was a convex one, rising across most of the range of CRs, but effectively flat for city-regions with populations of 1.5 million or more (about the size the Leeds $C R$ ) or others embedded within a London CCR covering virtually all the GSE.

This evidence that there are some clear (but distinct) geographic patterns to be explained for the two spatial factors was followed up by looking for evidence of more causal associations. The estimated values for each spatial factor were regressed on a small set of more substantive variables, reflecting both our initial hypotheses and the role identified for sectors of employment at the individual level in the first stage regressions. The set of independent variables comprised:

- industrial mix, favourableness for individual JS progress ${ }^{30}$

- occupational structure (\% professionals and large-firm managers)

- proportion of graduates in the (1991) working age population

- the 1991 unemployment rate (as an indicator of labour market slack)

- agglomeration, (using the combined CR/CCR measure), included as an indicator of likely labour market flexibility and informational externalities.

In the case of the elevator effect, the regression results (presented in Table 4) offered support only for the hypothesis that gains of this kind derived simply from quitting city-regions with a weak pressure of labour demand (where human capital assets might be supposed to be under-employed) for regions with tighter labour markets (where people with equivalent qualities and experience might access better jobs). Neither skill stocks, the employment mix, nor labour market thickness appeared to exert significant effects in this case.

\footnotetext{
${ }^{29}$ Shown in Figures A2(a), (b) and (c) of the statistical appendix..

${ }^{30}$ Averaging individual scores on the sectoral semi-dummies.
} 
Table 4

Regressions of Spatial Coefficients on Employment, Education and Agglomeration Indicators

\begin{tabular}{|l|c|c|c|c|}
\hline & \multicolumn{2}{|c|}{$\mathbf{1}$} & \multicolumn{2}{|c|}{$\mathbf{2}$} \\
\hline Constant & Elevator & Escalator & Elevator & Escalator \\
\hline Unemployment & $\begin{array}{c}0.0069 \\
(0.2)\end{array}$ & $\begin{array}{c}-0.0939^{* *} \\
(2.9)\end{array}$ & $\begin{array}{c}0.0795^{* * *} \\
(5.4)\end{array}$ & $\begin{array}{c}-0.1118^{* * *} \\
(3.8)\end{array}$ \\
\hline Graduates & $\begin{array}{c}-0.0455^{* * *} \\
(3.6)\end{array}$ & $\begin{array}{c}0.0086 \\
(0.8)\end{array}$ & $\begin{array}{c}-0.0512^{* * *} \\
(5.5)\end{array}$ & \\
\hline $\begin{array}{l}\text { High Level } \\
\text { Occupations }\end{array}$ & $\begin{array}{c}0.0003 \\
(0.2)\end{array}$ & $\begin{array}{c}-0.0029 \\
(1.6)\end{array}$ & & -0.0029 \\
$(1.0012$ & $0.0041^{*}$ & & $0.0038^{*}$ \\
Industrial Mix & $(0.6)$ & $(2.2)$ & & $(2.4)$ \\
(knowledge- \\
intensive and \\
dynamism)
\end{tabular}

Source: dependent variables as for Table 3, all other variables from the LS.

Notes: 1 . see notes for Table 3; 2. Unemployment and graduate variables relate to $1991 ; 3$. high level occupations variable is mean JS score for 1991; 4. industrial mix variable is a composite based on sectoral coefficients in the individual level regression, and relates nominally to 1996

For the escalator case, by contrast, all of these attributes of the CR of residence seemed to affect rates of progression. In particular, a concentration of jobs in higher level occupations and dynamic knowledge-intensive sectors - as well as agglomeration - did seem supportive of faster occupational progression, as hypothesised earlier. This finding has echoes of Glaeser and Resseger's emphasis on the positive effects of a concentration of graduates, except that it relates to demand-side externalities. Indeed controlling for the job mix, the impact of a larger proportion of graduates appears to be negative. There is at least a suggestion here that tightness in a cityregion's graduate labour market may stimulate upgrading of the workforce through on-the-job talent development ${ }^{31}$. When Glaeser and Resseger's analysis is approximated more closely, by omitting job-related variables (in results not reproduced here), the British data still yield

\footnotetext{
${ }^{31}$ Given that the share of higher occupations in the workforce is the best predictor of the proportion of graduates (with a coefficient close to 1 , a plausible alternative formulation of the model would replace both with the difference between them. In that case, this gap, industry mix and agglomeration all appear as (comparably) significant influences on the escalator effect.
} 
qualitatively different results - the graduate effect does then becomes positive (as they find for the US), but is clearly weaker than that of agglomeration (in contrast to what they find). This difference might perhaps reflect the more tightly integrated (less pluralistic) urban system of England and Wales, as compared with the US. However, the significance which we find for the knowledgeintensity of local employment (as distinct from the qualification level of workers) is consistent with hypotheses about the importance of the opportunity structure, and may have much more general significance.

The locational effects which we have identified on occupational achievement are significant and intelligible, but relatively modest in scale. For example, we find that moving out of the slack demand regions adds just $2 \%$ to the JS score, while ten years' residence in a major agglomeration would raise this score by some $5 \%$ more than in the least populous city-region. By comparison, de la Roca and Puga (2012) report that the first decade of work experience in Madrid adds $20 \%$ in earning power over and above what could be gained in an average Spanish city. In part this difference may reflect the fact that we have ignored all the progression that people can achieve within an occupational category. But it may also be that our averaging of escalator impacts effects across (virtually) the whole workforce, we conceal the extent of gains achieved by some sub-groups figuring more strongly in the experience-based analyses. Therefore we turn now to look for evidence of such variation..

\subsection{Variations/Concentrations Between Sub-Groups}

The conceptual discussion in section 2 suggested some simple hypotheses about groups which are likely to gain particularly from escalator/elevator processes. For the escalator, these are: those first entering a particular CR labour market during the previous 10-15 years; and those with high levels of dynamic human capital (learning capacity and motivation). For the elevator, they are those migrants from depressed areas whose under-exploited potential is more likely to be recognised by an employer elsewhere, most obviously the young. A further proposition, implied (at least) by Fielding, is that (inter-CR) migrants should gain more from the opportunities of an escalator region, whether through self-selection for favourable attributes (e.g. youth, education or enterprise) or perhaps because the act of migration overcomes inertia. 
To investigate such hypotheses, we return to the micro-level LS change analyses, looking first for evidence of significant interaction between the main personal and situational effects already identified, and then for evidence in quantile regressions of interactions between the situational effects and unobserved personal attributes. For this purpose, we start from a more parsimonious version of the original regression model: replacing the array of locational variables with a population-based agglomeration index (to capture the escalator effect) and the difference in (base year) unemployment rates between areas of residence in 1991 and 2001 (to capture the elevator effect); and summarising the effects of the substantive variables in five 'factors', relating to employment sector ('knowledge industries'), age/sex ('youth'), and base-year employment position, qualifications, and JS status ('mean reversion'). To test whether migrants enjoyed stronger escalator effects, a dummy variable for inter-CR migration during the previous decade was also included.

The analysis of interactions with personal factors identified a number of significant effects, though these were stronger for the sectoral factor than with the locational variables. In particular these suggested that both younger people and (less predictably) the less qualified gained more in terms of occupational advancement from working in the 'knowledge industries'. For the locational variables, however, there was no evidence that qualifications affected the strength of either escalator or elevator effects. There was a significant positive interaction effect between the agglomeration index and the reversion factor, implying a stronger tendency to equilibration from atypically high/low status positions in the larger urban labour markets. In relation to our hypotheses, the significant results were that the young did prove to be substantially more responsive to both escalator and elevator effects, whereas there was no evidence of this kind for inter-CR migrants (Table 5). 
Table 5

JS Change Regressions: Tests of Interaction with Locational Factors

\begin{tabular}{|c|c|c|}
\hline Variable & 1 & 2 \\
\hline $\begin{array}{l}\text { Escalator } \\
\text { Agglomeration*Youth }\end{array}$ & $\begin{array}{c}0.0027^{* * *} \\
(3.9)\end{array}$ & $\begin{array}{c}0.0026^{* * *} \\
(3.8)\end{array}$ \\
\hline Agglomeration*Qualification & $\begin{array}{c}-0.0006 \\
(0.7)\end{array}$ & \\
\hline Agglomeration*Knowledge Ind. & $\begin{array}{c}0.0004 \\
(0.5) \\
\end{array}$ & \\
\hline Agglomeration*Mean Reversion & $\begin{array}{c}0.0019^{*} \\
(2.2)\end{array}$ & $\begin{array}{c}0.0018^{*} \\
(2.6) \\
\end{array}$ \\
\hline Agglomeration*Migrant 8191 & & $\begin{array}{c}0.0004 \\
(0.2) \\
\end{array}$ \\
\hline $\begin{array}{l}\text { Elevator } \\
\text { UEdiff*Youth }\end{array}$ & $\begin{array}{c}-0.264^{*} \\
(2.4)\end{array}$ & $\begin{array}{c}-0.276^{*} \\
(2.5) \\
\end{array}$ \\
\hline UEdiff*Qualification & $\begin{array}{c}0.0628 \\
(0.6) \\
\end{array}$ & \\
\hline UEdiff*Knowledge Industry & $\begin{array}{c}-0.094 \\
(0.8) \\
\end{array}$ & \\
\hline UEdiff*Mean Reversion & $\begin{array}{c}0.0033 \\
(0.8) \\
\end{array}$ & \\
\hline UEdiff*Migrant 8191 & & $\begin{array}{c}-0.055 \\
(1.0) \\
\end{array}$ \\
\hline $\mathrm{N}$ & 145605 & 145605 \\
\hline $\mathrm{R}^{2}$ & 0.240 & 0.240 \\
\hline RMSE & 0.254 & 0.254 \\
\hline
\end{tabular}

Source: see Table 1

Notes: 1. The dependent variable is (again) JS change between 1991 and 2001; 2. In addition to the reported interactions with spatial variables, the regressions included a set of main effects and additional interactions with the sectoral variable ${ }^{32}$. 2. The interaction terms have been scaled so that coefficients represent the increment to a main effect of a 1 SD shift in value on the interacting factor. 3 . $t$ statistics are based on robust standard errors with allowance for clustering of spatial variables.

Although youth thus seemed to boost both kinds of spatial effect, disaggregated JS regressions for specific age groups showed it to operate in quite different ways for escalator and elevator effects. In the former case, there seem actually to be clear gains right through the working age range, though the impact was between 3 and 4 times as strong among those aged under 25 (at the start of the decade) as among the over 40s (Table 6). This looks broadly consistent with the evidence from the spatial economists (reported earlier) on the attenuation of gains from experience over

\footnotetext{
${ }^{32}$ Full results are reported in Table A6 of the statistical appendix. .
} 
extended periods in a metro region. In the case of the elevator effect, however, significant gains were concentrated much more narrowly, just among those aged 20-24 at the start of the period. This pattern is at least consistent with the idea that among migrants from slack labour markets, it is the youngest who are most likely to be recognised by employers elsewhere as having unexploited potential, not yet being durably marked down by/for their work histories.

\section{Table 6 Disaggregated JS Change Regressions: Escalator and Elevator Effects by Age}

\begin{tabular}{|l|c|c|c|c|c|c|}
\hline & $\mathbf{1 6 - 1 9}$ & $\mathbf{2 0 - 2 4}$ & $\mathbf{2 5 - 2 9}$ & $\mathbf{3 0 - 3 9}$ & $\mathbf{4 0 - 4 9 / 5 4}$ & ALL \\
\hline Escalator: & $\begin{array}{c}.020^{* * *} \\
(6.3)\end{array}$ & $\begin{array}{c}.017^{* * *} \\
(9.0)\end{array}$ & $\begin{array}{c}.009^{* * *} \\
(5.4)\end{array}$ & $\begin{array}{c}.005^{* * *} \\
(4.6)\end{array}$ & $\begin{array}{c}.005^{* * *} \\
(5.0)\end{array}$ & $\begin{array}{c}.008^{* * *} \\
(12.6)\end{array}$ \\
\hline Egglomeration Population (In) & -.155 & $\begin{array}{c}-1.7124^{* * *} \\
(4.2)\end{array}$ & $\begin{array}{c}-.431 \\
(1.8)\end{array}$ & $\begin{array}{c}-.325 \\
(1.5)\end{array}$ & $\begin{array}{c}-.211 \\
(1.0)\end{array}$ & $\begin{array}{c}-.475^{* * *} \\
(4.3)\end{array}$ \\
\hline Differential unemployment rate & $(0.3)$ & & & & & \\
\hline $\mathbf{N}$ & & & & & & \\
\hline $\mathbf{R}^{\mathbf{2}}$ & 7651 & 19270 & 22409 & 41782 & 54730 & 145852 \\
\hline SMSE & 0.268 & 0.264 & 0.238 & 0.221 & 0.205 & 0.240 \\
\hline
\end{tabular}

Source: see Table 1

Note: Additional variables in the regressions included the youth, JS1991, qualification, knowledge industry and economic position factors (as in Table 5), together with interactions between the first three of these and the industry factor.

To explore the last of the hypotheses, about the potential impact of dynamic (but unmeasured) personal attributes in reaping greater returns from the opportunities offered by spatial escalators or elevators, we turn to quantile versions of these regressions. The rationale is that different points in the error distribution from a common JS change regression should reflect the value of these dynamic assets, and that if these reinforced contextual factors the latter would attract significantly higher coefficients in regressions for the higher quantiles. For intelligibility, the substantial proportion of individuals with an unchanged occupation has been excluded from this analysis ${ }^{33}$, explicit interaction effects have been omitted, and summary results are presented just for the quartiles (Table 7). From these it can be seen that almost all variables (other than the qualification factor) showed significant variations in coefficients, implying a general tendency for their effects on

\footnotetext{
${ }^{33}$ An adapted Heckman procedure was used to control for sample selection bias, but though statistically significant its substantive impact is small. Exclusion of those without an occupational change naturally inflates all coefficient estimates, by around one third. After allowing for this, however, comparison of mean regressions - undertaken as a robustness check - shows that only estimates of the reversion factor are clearly sensitive to inclusion/exclusion of the no-change group (see Table A7 of the statistical appendix).
} 
individuals' progression to be conditioned by some important unobserved influence. This is most striking in the case of (negative) ageing effects (i.e. the inverse of the youth factor) which seem to bear down most strongly on those whose unobserved attributes (e.g. dynamic human capital) are generally least advantageous. In relation to the (positive) escalator and elevator effects represented here by the agglomeration and differential unemployment variables - the logic is reversed, in that those who gain most from these seem to be those who are best endowed in these terms. For the escalator effect at least this is consistent with the hypothesis about the role of jobrelated ambition - while for the elevator it is at least credible that such ambition could enhance the perceived potential of some of the previously under-employed migrants from depressed regions.

Table 7

Quantile Regressions of JS Change on Personal, Sectoral and Locational Factors

\begin{tabular}{|l|c|c|c|}
\hline Variable & Upper Quartile & Median & Lower Quartile \\
\hline Constant & 3.421 & 3.818 & 3.881 \\
\hline Mean Reversion Factor & 1.209 & 1.319 & 1.537 \\
\hline Economic Position in 1991 Factor & 1.015 & 1.561 & 1.418 \\
\hline Youth Factor & 0.659 & 1.226 & 1.701 \\
\hline Qualification Factor & 1.261 & 1.545 & 1.312 \\
\hline Knowledge Industry Factor & 1.478 & 1.441 & 1.385 \\
\hline Agglomeration (log pop) & 0.0171 & 0.0121 & 0.0091 \\
\hline Unemployment Differential & -0.914 & -0.697 & -0.267 \\
\hline & & & -0.027 \\
\hline Inverse Mills Ratio (IMR) & -1.447 & -1.558 & 0.238 \\
\hline IMR squared & 0.851 & 1.210 & 90845 \\
\hline N & 90845 & 90845 & 0.152 \\
\hline Pseudo R & 0.219 & 0.166 & \\
\hline
\end{tabular}

Source: see Table 1

Notes: 1 . These analyses relate to a restricted observation set (as compared with earlier analyses), excluding all those with the same recorded SOC90 occupation in both Censuses. 2. Variables are defined as in the upper part of Table 5 (excluding the interaction terms). 3 The IMS terms are controls for sample selection bias; 4 . The differences between upper quartile and lower quartile coefficients are significant at the $0.1 \%$ level for all variables apart from the industry factor (significant at 1\%) and the qualification factor (not significant even at 10\%)

Inspection of coefficients on the relevant (agglomeration and differenced unemployment) variables across a finer set of quantiles confirms that the inter-quartile variation is part of a more general pattern extending across the full distribution ${ }^{34}$. The relation is not simply linear, however, but in each case involves zero effects at the very bottom of the distribution, but with monotonic increases

\footnotetext{
${ }^{34}$ See Figures $\mathrm{A} 3 \mathrm{a}$ and $\mathrm{A} 3 \mathrm{~b}$ in the statistical appendix.
} 
up to the $65 \%$ quantile, and then effectively flat-lining. For the escalator this is broadly consistent with Gordon's (2013) finding about the relation with a (survey-based) measure of job-related ambition, with those in the top $60 \%$ as a whole showing similarly strong benefits in terms of occupational progression from residence in an escalator region, while the few with zero ambition experienced none.

Further analyses, applying the quantile approach to specific age groups, demonstrate that this heterogeneity in impacts of both escalator and elevator processes operates across the age ranges with the two sources of variation in their strength (youthfulness and unobserved personal attributes) compounding. Among the upper quartile of the younger working age groups, the estimated impacts of both escalator and elevator effects are roughly double the mean values reported at the end of -section 4.2.

\section{Conclusion}

Two decades after the period in which Fielding (1989) found a social class 'escalator' operating in South East England, it still appeared to be functioning at least as effectively, and maybe more so than before the 1990s (Champion et al., 2013). Broadening the focus to consider progression across the full range of occupations, while controlling for a range of personal factors which might have exaggerated the role of the region in simple comparisons, we still find this escalator to be a significant influence on differential rates of labour market success within England and Wales. Neither London nor the wider South East region, however, actually seem to have a monopoly on its operation. And, though these may contain the most supportive kinds of opportunities for those with job-focused ambitions and display the strongest inter-class mobility (Champion et al., 2013), we find purely locational advantages to be about as strong in a number of second and third order CRs.

Two latent ambiguities in Fielding's original work involved the questions:

- whether the escalator is really a regional/cultural phenomenon (of South East England as home to the dominant class) or an urban/economic one (peaking in London as a largest agglomeration and highest order centre); and 
- how crucial geographic mobility is to social progression, as distinct from simply residence within an escalator city or region.

In this paper we make a much sharper distinction between the pure escalator, available to all residents of the advantaged areas, and an elevator, potentially raising or lowering the position of labour migrants according to the direction of their movement. And, consistent with our theoretical hypotheses, we find empirically that:

- the elevator is an inter-regional phenomenon directly reflecting differences in the relative tightness of spatial labour markets; while

- the escalator is an urban phenomenon reflecting both pure agglomeration and the concentration of advanced activities and expanding sectors in the 'highest order' cityregions, and does not privilege migrants over established residents in its effects.

As we see it, agglomeration is supportive of occupational progression - as of the accelerated earnings growth found by Glaeser and Resseger (2010) and de la Roca and Puga (2013) - because of its contribution to 'on the job' development of (largely tacit) capabilities and productive connections, particularly by those with some measure of 'job-related ambition', for whom it continues to display a particular attraction. Part of the connection doubtless lies in the potential that thick labour markets offer for parlaying occupational success into pecuniary advantage, as Glaeser and Mare (2001) argued. But it also relates to the particular role of the 'communities of practice' in the context of successful urban agglomerations. Beyond simple membership of such a community, their contribution to occupational advance depends crucially on the premium attached to the kinds of capability (and networks) to which a particular 'community' provides access for its more ambitious members. Put crudely, it is the kind of job opportunities available that matters more than a simple concentration of human capital. But it is also a matter of the structure and spatial/organisational articulation of such communities (Amin and Roberts, 2008). Both factors contribute to the extremely strong role which our analyses show to be played by sectoral factors, with employment in knowledge-intensive and dynamic sectors demonstrably boosting progression by much more than any location, even in the most thick and dynamic agglomeration. Additionally though, the advantage of such areas for the occupationally ambitious stems partly from the potential for accumulating a distinctive portfolio of capabilities from a range of different local practice communities (Iskander, 2013), partly from the extension that their overlaps provide across 
the wider city regions and amalgams of these, which our results show to be the relevant scale for strong escalators, and partly from the active interfacing with international knowledge networks achieved within the highest order city-regions and the most dynamic sectors.

As Fielding (1989) suggested, occupational 'escalators' in core regions / agglomerations seem to be a significant element in the complex of 'cumulative' processes sustaining and reinforcing uneven spatial development within countries such as the UK. They do need to be seen, however, as producing not simply social advancement but real additions to human capital and productive capacity at the national/continental scale, which are not lightly to be cast aside in the interests of greater spatial equity. The results of our analyses suggest, however, that London - and even the wider Greater South East - are not unique within a British context in their capacity to promote escalation, which could also be pursued in second and third order cities/CRs. They also point to the critical importance of concentrations of the kind of job offering advanced learning opportunities, and not simply the availability of 'talented' and qualified workers for securing occupational upgrading in CRs outside the Greater South East. 


\section{References}

Amin, A. and Roberts, J. (2008) 'Knowing in action: beyond communities of practice', Research Policy, 37, 353-369.

Bosio, G. (2009) 'Temporary employment and wage gap with permanent jobs: evidence from quantile regression', Department of Economics and Business Studies, University of Milan http://mpra.ub.uni-muenchen.de/16055/1/MPRA paper 16055.pdf

Buchinsky M. (2001), 'Quantile regression with sample selection: Estimating women's return to education in the U.S.', Empirical Economics, 26, 87-113.

Buck, N., Gordon, I., Hall, P., Harloe, M. and Kleinman, M. (2002) Working Capital: life and labour in contemporary London, London: Routledge.

Coombes, M. (2002) 'Localities and City Regions Codebook', in The Census Data System (eds. P. Rees, D. Martin and P. Williamson), Chichester: Wiley.

Champion, A.G. (2012) 'Testing the return migration element of the 'escalator region' model: an analysis of migration into and out of south-east England, 1966-2001', Cambridge Journal of Regions, Economy and Society, 5, 255-270.

Champion, A.G., Coombes, M. and Gordon, I.R. (2013) 'How far do England's second-order cities emulate London as "escalators" of human capital?', Population, Space and Place, doi: 10.1002/psp.1806.

De la Roca, J. and Puga, D. (2012). 'Learning by Working in Big Cities', CEPR Discussion Paper, 9243, Centre for Economic Policy Research.

Elias, P. and Blanchflower, D. (1987) 'Local labour market influences on early occupational achievement' in I. Gordon (Ed.), Unemployment, regions and labour market: reactions to recession, Pion Press, pp.158-171.

Evans, A.W. (1990) 'The assumption of equilibrium in the analysis of migration and interregional differences: a review of some recent research', Journal of Regional Science, 515-531.

Fielding, A.J. (1989) 'Inter-regional migration and social change: a study of South East England based upon data from the Longitudinal Study', Transactions of the Institute of British Geographers, NS 14: 24-36.

Fielding, A. J. (1992) 'Migration and social mobility: South East England as an escalator region'. Regional Studies, 26: 1-15.

Fielding, A. J. (1993) 'Migration and the metropolis: an empirical and theoretical analysis of interregional migration to and from south east England', Progress in Planning, 39: 71-166.

Fielding, A. (1995) 'Migration and middle-class formation in England and Wales 1981-91', in Butler, T. and Savage, M. (eds.) Social Change and the Middle Classes. London: UCL Press.

Findlay, A.M., Mason, C., Harrison, R., Houston, D. and McCollum, D. (2008) 'Getting off the escalator?', Environment and Planning A, 40, 2169-85.

Findlay, A. Mason, C. Houston, D. McCollum. D, and Harrison, R. (2009). 'Escalators, elevators and travelators: the occupational mobility of migrants to South-East England'. Journal of Ethnic and Migration Studies, 35, 861-879.

Florida,R., (2002) 'Bohemia and economic geography', Journal of Economic Geography, 2, 55-71.

Glaeser, E.L. and Maré, D.C. (2001) 'Cities and Skills.' Journal of Labor Economics. 19, 316-342.

Glaeser, E. L., and Resseger, M.G. (2010) 'The complementarity between cities and skills', Journal of Regional Science, 50, 221-244.

Gordon, I.R. (2013) 'Ambition, Human Capital Acquisition and the Metropolitan Escalator', Regional Studies, DOI:10.1080/00343404.2013.799767.

Hall, P.G. (1989) London 2001, London: Unwin Hyman. 
Iskander, N. (2013). 'Learning in Place: Immigrants' Spatial and Temporal Strategies for Occupational Advancement Immigrants in Space and Time', Economic Geography 89, 53-76.

Marglin, S. A. (1987) Growth, Distribution and Prices, Cambridge, MA: Harvard Univ. Press.

Massey, D. (1984) Spatial Divisions of Labour: social structures and the geography of production, London: Macmillan.

Molho, I.I. (1986) 'Theories of migration: a review', Scottish Journal of Political Economy, 33, 396419.

Newbold, K.B. and Brown, W.M. (2012) 'Testing and Extending the Escalator Hypothesis: Does the Pattern of Post-migration Income Gains in Toronto Suggest Productivity and/or Learning Effects?', Urban Studies, 49, 3447-3465

Nickell, S.J. (1982) 'The Determinants of Occupational Success in Britain', Review of Economic Studies, 49, 43-53. .

Peri, G. (2002) 'Young Workers, Learning and Agglomerations', Journal of Urban Economics, 52, 582-607.

Peri, G. (2006) 'Local human capital externalities: an overlapping generation model and some evidence on experience premia', Review of Economic Studies, 73, 381-412.

Sjastaad, L.A. (1962) 'The Costs and Returns of Human Migration', Journal of Political Economy, 70, 80-93.

Williams, A.M, and Baláž, V. (2012) 'Migration, Risk, and Uncertainty: Theoretical Perspectives', Population, Space and Place, 18, 167-180 
STATISTICAL APPENDIX

\section{Table A1: City Regions and Consolidated City-regions}

\begin{tabular}{|c|c|}
\hline City Region & Consolidated City region \\
\hline Middlesbrough & Middlesbrough \\
\hline Carlisle & Carlisle \\
\hline Leeds & \multirow[t]{3}{*}{ Leeds-Bradford-York } \\
\hline York & \\
\hline Bradford & \\
\hline Hull & Hull \\
\hline Sheffield & Sheffield \\
\hline Manchester & \multirow[t]{4}{*}{ Manchester-Liverpool-Stoke } \\
\hline Preston & \\
\hline Liverpool & \\
\hline Stoke & \\
\hline Chester & Chester \\
\hline Nottingham & \multirow[t]{3}{*}{ Nottingham-Derby-Lincoln } \\
\hline Lincoln & \\
\hline Derby & \\
\hline Leicester & Leicester \\
\hline Birmingham & \multirow[t]{2}{*}{ Birmingham-Coventry } \\
\hline Coventry & \\
\hline Shrewsbury & Shrewsbury \\
\hline Bristol & Bristol \\
\hline Worcester & \multirow{3}{*}{ Gloucester-Worcester-Oxford } \\
\hline Gloucester & \\
\hline Oxford & \\
\hline Cardiff & Cardiff \\
\hline Swansea & Swansea \\
\hline Plymouth & \multirow[t]{2}{*}{ Plymouth-Exeter } \\
\hline Exeter & \\
\hline Norwich & Norwich \\
\hline Northampton & \multirow[t]{7}{*}{ London Region } \\
\hline Peterborough & \\
\hline Cambridge & \\
\hline Ipswich & \\
\hline London & \\
\hline Reading & \\
\hline Brighton & \\
\hline Southampton & Southampton-Portsmouth \\
\hline
\end{tabular}


Table A2

Regressions of JS Change : Coefficients on Personal Attributes

\begin{tabular}{|c|c|c|}
\hline & Model 1 & Model 4 \\
\hline Constant & $\begin{array}{c}2.169^{\star \star \star} \\
11.1\end{array}$ & $\begin{array}{c}2.965^{\star \star \star} \\
15.2\end{array}$ \\
\hline $\begin{array}{l}\text { Employment Status, 1991: } \\
\text { Full-time Employee }\end{array}$ & $\begin{array}{c}0.028^{\star \star \star} \\
10.8\end{array}$ & $\begin{array}{c}0.004 \\
1.6\end{array}$ \\
\hline Part-time Employee & $\begin{array}{c}0.005 \\
1.6\end{array}$ & $\begin{array}{c}-0.021^{\star \star *} \\
-6.3\end{array}$ \\
\hline Employer & 0 & 0 \\
\hline Self-Employed & $\begin{array}{c}0.031^{\star \star \star} \\
7.5\end{array}$ & $\begin{array}{c}0.053^{* \star *} \\
13.0\end{array}$ \\
\hline $\begin{array}{l}\text { Job Status, } 1991 \\
\text { JS Value }\end{array}$ & $\begin{array}{c}-0.797^{* * *} \\
-6.0\end{array}$ & $\begin{array}{c}-1.658^{\star \star *} \\
-12.4\end{array}$ \\
\hline JS Squared & $\begin{array}{c}0.206^{* *} \\
2.9\end{array}$ & $\begin{array}{c}0.571^{* * *} \\
8.1\end{array}$ \\
\hline JS Cubed & $\begin{array}{c}-0.038^{* *} \\
-3.1 \\
\end{array}$ & $\begin{array}{c}-0.093^{\star \star \star} \\
-7.6 \\
\end{array}$ \\
\hline $\begin{array}{l}\text { Age \& Sex, } 1991 \\
\text { Age }\end{array}$ & $\begin{array}{l}0.006^{* *} \\
2.8\end{array}$ & $\begin{array}{l}0.006^{\star *} \\
2.9\end{array}$ \\
\hline Log Age & $\begin{array}{c}-0.322^{\star \star \star} \\
-4.6\end{array}$ & $\begin{array}{c}-0.323^{\star \star \star} \\
-4.7\end{array}$ \\
\hline Female & $\begin{array}{c}-0.559^{\star \star \star} \\
-6.8\end{array}$ & $\begin{array}{c}-0.535^{\star \star \star} \\
-6.7\end{array}$ \\
\hline Age*Female & $\begin{array}{c}-0.005^{\star \star \star} \\
-4.9\end{array}$ & $\begin{array}{c}-0.005^{\star \star \star} \\
-4.9\end{array}$ \\
\hline Log Age* Female & $\begin{array}{c}0.196^{\star \star \star} \\
5.8 \\
\end{array}$ & $\begin{array}{c}0.184^{\star \star \star} \\
5.6\end{array}$ \\
\hline $\begin{array}{l}\text { Qualifications (18+), } 1991 \\
\text { None }\end{array}$ & $\begin{array}{c}-0.169 \\
-1.1\end{array}$ & $\begin{array}{c}-0.226 \\
-1.6\end{array}$ \\
\hline None*Age & $\begin{array}{c}-0.001 \\
-0.4\end{array}$ & $\begin{array}{c}-0.001 \\
-0.6\end{array}$ \\
\hline None*Log Age & $\begin{array}{c}0.005 \\
0.1\end{array}$ & $\begin{array}{c}0.027 \\
0.5\end{array}$ \\
\hline $\begin{array}{l}\text { Escalator/Elevator Semi- } \\
\text { dummies }\end{array}$ & .. & $\mathrm{X}$ \\
\hline Sectoral Semi-dummies & .. & $\mathrm{X}$ \\
\hline
\end{tabular}

Source: analyses of unpublished 1991/ 2001 Census linked micro-data from ONS Longitudinal Study Notes: This table presents results for the personal attribute variables (only) from the regressions summarily reported in Table 2 of the paper. 
Table A3

JS Change Regressions: Coefficients on Sectoral Semi-dummies SIC (2 digit) Divisions with Significantly Stronger or Weaker Job Status Progression

\begin{tabular}{|c|c|c|c|}
\hline & Coefficient & t statistic & $\begin{array}{l}\text { Significance } \\
\text { level }\end{array}$ \\
\hline $\begin{array}{l}\text { Significantly Above Average } \\
72 \text { : Computing and related activities }\end{array}$ & 0.258 & 7.0 & $* * *$ \\
\hline 467 : Auxiliary financial activities & 0.171 & 4.5 & $* * *$ \\
\hline 65 : Financial intermediation & 0.115 & 3.1 & $* *$ \\
\hline 66 : Insurance and pension funding & 0.111 & 3.0 & $* *$ \\
\hline 30 : Office machinery and computers & 0.098 & 2.5 & $*$ \\
\hline $80:$ Education & 0.085 & 2.4 & * \\
\hline 70 : Real estate activities & 0.079 & 2.1 & $*$ \\
\hline 75 : Public administration & 0.077 & 2.1 & * \\
\hline 41: Water services & 0.080 & 2.1 & * \\
\hline 73 : Research and development & 0.079 & 2.0 & * \\
\hline $17:$ Textiles & -0.083 & -2.2 & $*$ \\
\hline $\begin{array}{l}\text { Significantly Below Average } \\
52: \text { Retail trade }\end{array}$ & -0.097 & -2.7 & $* *$ \\
\hline 90 : Sewage, refuse disposal and sanitation & -0.109 & -2.8 & $* *$ \\
\hline $11 / 13$ : Extraction of oil and natural gas & -0.104 & -2.8 & $* *$ \\
\hline 60 : Land transport; & -0.108 & -3.0 & $* *$ \\
\hline $10:$ Coal Mining & -0.121 & -3.1 & $* *$ \\
\hline 19 : Tanning and dressing of leather & -0.126 & -3.1 & $* *$ \\
\hline 18 : Apparel; dressing/dyeing fur & -0.133 & -3.5 & $* * *$ \\
\hline 93 : Other service activities & -0.142 & -3.9 & $* * *$ \\
\hline 55 : Hotels and restaurants & -0.166 & -4.6 & $* * *$ \\
\hline
\end{tabular}

Source: as for Table A2.

Notes: 1 . This table presents (significant) coefficient estimates for sectoral variables from the (model 3 ) regression summarily reported in Table 1 of the paper; 2 . Effect estimates and significance tests relate to deviations from the national mean; 3 . asterisks indicate significance levels: ${ }^{*}=5 \% ;{ }^{*}=1 \% ;{ }^{* *}=0.1 \%$. 
Table A4

JS Change Regression: City Regions with Significantly Stronger or Weaker JS Progression

\begin{tabular}{|c|c|c|c|c|c|c|c|}
\hline & \multicolumn{3}{|c|}{ Elevator Effects } & \multicolumn{3}{c|}{ Escalator Effects } \\
\hline & Coeff & T value & Sig & & Coeff & T value & Sig \\
\hline Significantly Above Average & & & & & & & \\
Reading & & & & & & & \\
\hline Cambridge & 0.024 & $\mathbf{2 . 0 1 1}$ & $*$ & Reading & 0.022 & 3.468 & $* * *$ \\
\hline Significantly Below Average & 0.028 & 1.984 & $*$ & London & 0.014 & $\mathbf{2 . 6 9 8}$ & $* *$ \\
\hline Hull & & & & & & & \\
\hline
\end{tabular}

Source and Notes: as for Table A3, but for locational rather than sectoral variables. 
Table A6 JS Change Regression: Tests of Interaction Effects

\begin{tabular}{|c|c|c|c|}
\hline Variable & 1 & 2 & 3 \\
\hline Constant & $2.609 * * *(60.9)$ & $1.833 * * *(10.4)$ & $1.903 * * *(11.5)$ \\
\hline $\begin{array}{l}\text { Main effects } \\
\text { Mean Reversion Factor }\end{array}$ & $1.0 * * *(139.1)$ & $0.898 * * *(19.4)$ & $0.908 * * *(24.4)$ \\
\hline Economic Position 1991 Factor & $1.0 * * *(13.5)$ & $1.022 * * *(19.0)$ & $1.033^{* * *}(19.2)$ \\
\hline Youth Factor & $1.0 * * *(31.6)$ & $0.385 *(2.4)$ & $0.407 *(2.6)$ \\
\hline Qualification Factor & $1.0 * * *(80.5)$ & $1.173^{* * *}(9.5)$ & $1.007^{* * *}(77.1)$ \\
\hline Knowledge Industry Factor & $1.0 * * *(80.6)$ & $0.950 * * *(8.9)$ & $1.002 * * *(92.0)$ \\
\hline Agglomeration (log pop) & $.0082 * * *(5.7)$ & $0.0079 * * *(12.6)$ & $0.0077^{* * *}(11.0)$ \\
\hline Unemployment Differential & $-0.480 * *(2.8)$ & $-0.413 * * *(3.6)$ & $-0.453^{* * *}(4.0)$ \\
\hline InterCCR Migrant 1981-91 & & & $0.0215(1.1)$ \\
\hline $\begin{array}{l}\text { Interactions } \\
\mathrm{K} \text { Industry*Mean Reversion }\end{array}$ & & $-0.0037 * * *(5.0)$ & $-0.0035 * * *(4.7)$ \\
\hline K Industry*Youth & & $0.0049 * * *(7.1)$ & $0.0046^{* * *}(6.7)$ \\
\hline K Industry*Qualification & & $-0.0065 * * *(7.8)$ & $-0.0064 * * *(7.8)$ \\
\hline Agglomeration*Youth & & $0.0027^{* * *}(3.9)$ & $0.0026^{* * *}(3.8)$ \\
\hline Agglomeration*Qualification & & $-0.0006(0.7)$ & \\
\hline Agglomeration*Knowl Industry & & $0.0004(0.5)$ & \\
\hline Agglomeration*Mean Reversion & & $0.0019 *(2.2)$ & $0.0018 *(2.6)$ \\
\hline UEdiff*Youth & & $-0.264 *(2.4)$ & $-0.276 *(2.5)$ \\
\hline UEdiff*Qualification & & $0.0628(0.6)$ & \\
\hline UEdiff*Industry & & $-0.094(0.8)$ & \\
\hline UEdiff*Mean Reversion & & $0.0033(0.8)$ & \\
\hline Agglomeration*Migrant 8191 & & & $0.0004(0.2)$ \\
\hline UEdiff*Migrant 8191 & & & $-0.055(1.0)$ \\
\hline $\mathrm{N}$ & 145605 & 145605 & 145605 \\
\hline $\mathrm{R}^{2}$ & 0.239 & 0.240 & 0.240 \\
\hline RMSE & 0.254 & 0.254 & 0.254 \\
\hline
\end{tabular}

Source: as for Table A2.

Notes: 1. This table presents full results for the interaction models partially reported in Table 5 of the paper. 2. The dependent variable is (again) JS change between 1991 and 2001; 2. the five constructed 'factors' (mean reversion, employment position, youth, qualification and knowledge industry) are specified to attract unit coefficients in the 'main effects' regression (column 1). For the interaction effects, however, each of these (only) has been standardised (with mean zero and unit SD), so coefficients on the interaction terms represent the increment to a main effect of a $1 \mathrm{SD}$ shift in value on the interacting factor. 3. $t$ statistics are based on robust standard errors with allowance for clustering of spatial variables 
Table A7 Robustness Test: JS Change Regressions

\begin{tabular}{|l|c|c|c|c|}
\hline & Whole Sample & \multicolumn{2}{|c|}{ Occupation Changers } & Ratio \\
\hline & $\begin{array}{l}\text { (1) } \\
\text { OLS }\end{array}$ & $\begin{array}{c}\text { (2) } \\
\text { OLS }\end{array}$ & $\begin{array}{c}\text { (3) } \\
\text { Heckman } \\
\text { Corrected }\end{array}$ & (1): (3) \\
\hline Constant & 2.001 & 2.757 & 2.692 & 0.74 \\
\hline $\begin{array}{l}\text { Main effects } \\
\text { Fean Reversion }\end{array}$ & 1.027 & 1.475 & 1.458 & $0.70^{* * *}$ \\
\hline $\begin{array}{l}\text { Economic Position } \\
\text { 1991 Factor }\end{array}$ & 1.025 & 1.528 & 1.639 & 0.63 \\
\hline Youth Factor & 0.276 & 0.304 & 0.233 & 1.19 \\
\hline Qualification Factor & 1.168 & 1.580 & 1.577 & 0.74 \\
\hline $\begin{array}{l}\text { Knowledge Industry } \\
\text { Factor }\end{array}$ & 1.904 & 2.783 & 2.768 & 0.69 \\
\hline $\begin{array}{l}\text { Agglomeration (log } \\
\text { pop) }\end{array}$ & 0.008 & 0.013 & 0.012 & 0.64 \\
\hline $\begin{array}{l}\text { Unemployment } \\
\text { Differential }\end{array}$ & -0.406 & -0.409 & -0.434 & 0.94 \\
\hline $\begin{array}{l}\text { Interactions } \\
\text { K Industry*Mean } \\
\text { Reversion }\end{array}$ & -0.299 & -0.275 & -0.269 & 1.11 \\
\hline K Industry*Youth & 1.716 & 2.412 & 2.411 & 0.71 \\
\hline K Industry*Qual & -1.472 & -3.009 & -3.006 & $0.49^{*}$ \\
\hline Agglomeration*Youth & 0.057 & 0.077 & 0.077 & 0.74 \\
\hline UEdiff*Youth & -6.346 & -12.301 & -12.240 & 0.52 \\
\hline Source as for Tabl A2 & & & & \\
\hline
\end{tabular}

Source: as for Table A2.

Note: 1 . Asterisks in the last column relate to the significance of departures from an overall average ratio of 0.76 (reflecting the dilution of all effects across the full sample including occupational stayers). Significance levels are computed via the standard error of the difference between pairs of coefficient estimates (after allowance for the dilution effect. 
Figure A1: Map of the CURDS City Regions

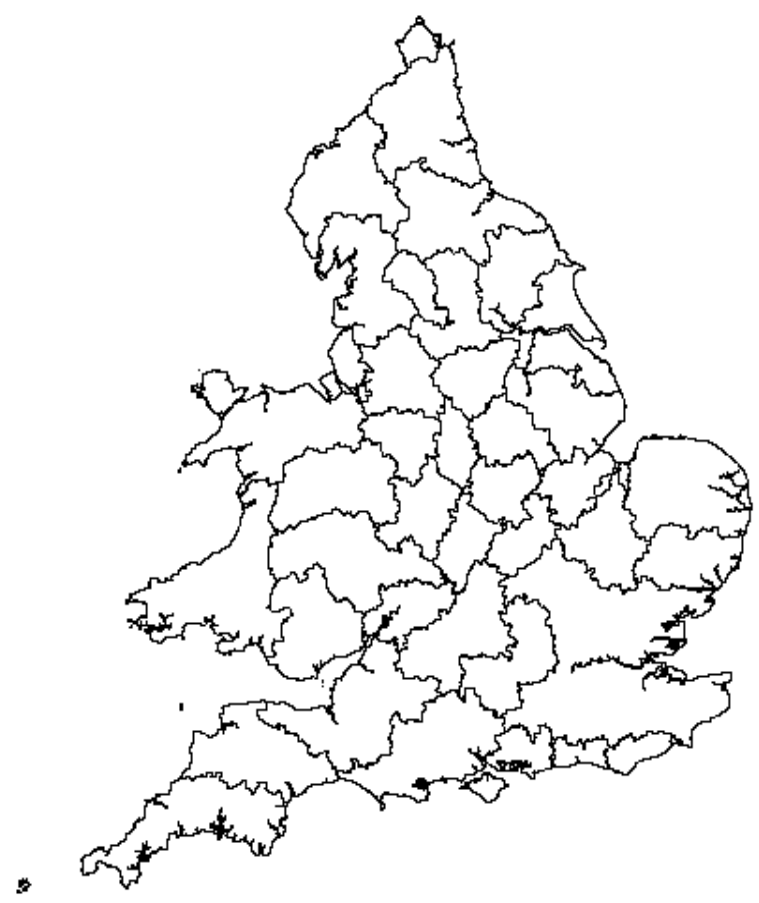

Source: M. Coombes, CURDS, Newcastle University

Figure A2: Plots of Estimated Escalator Effects Against Logged Population Size - with Kernel Regression

(a) City-Regions

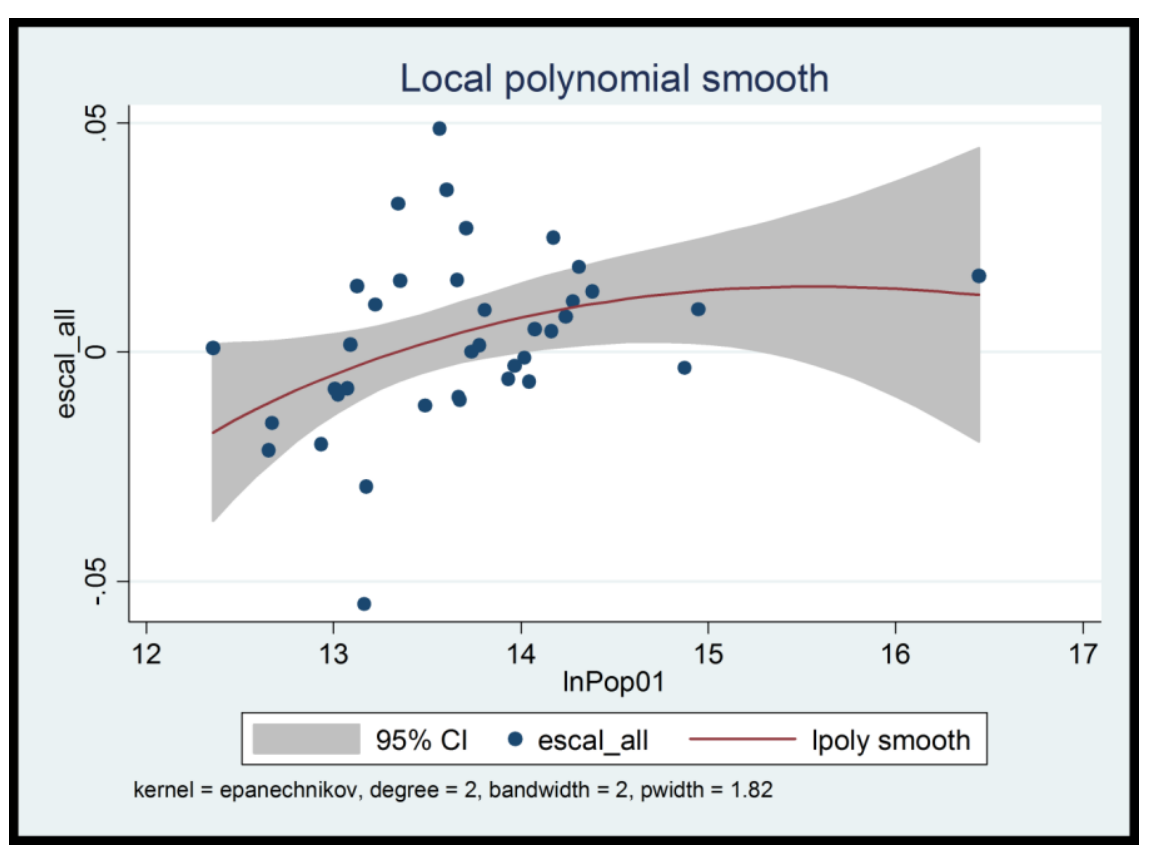




\section{(b) Consolidated City-Regions}

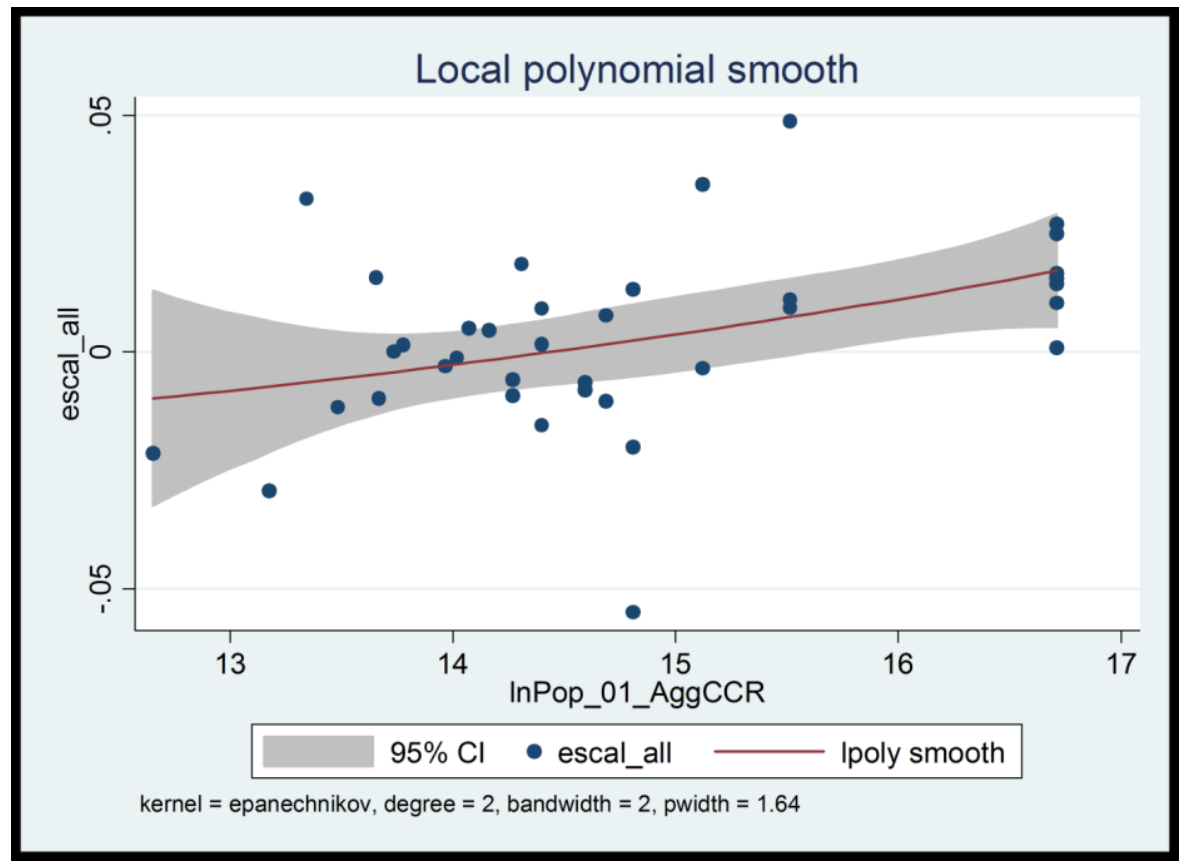

(c) Combined Agglomeration Measure

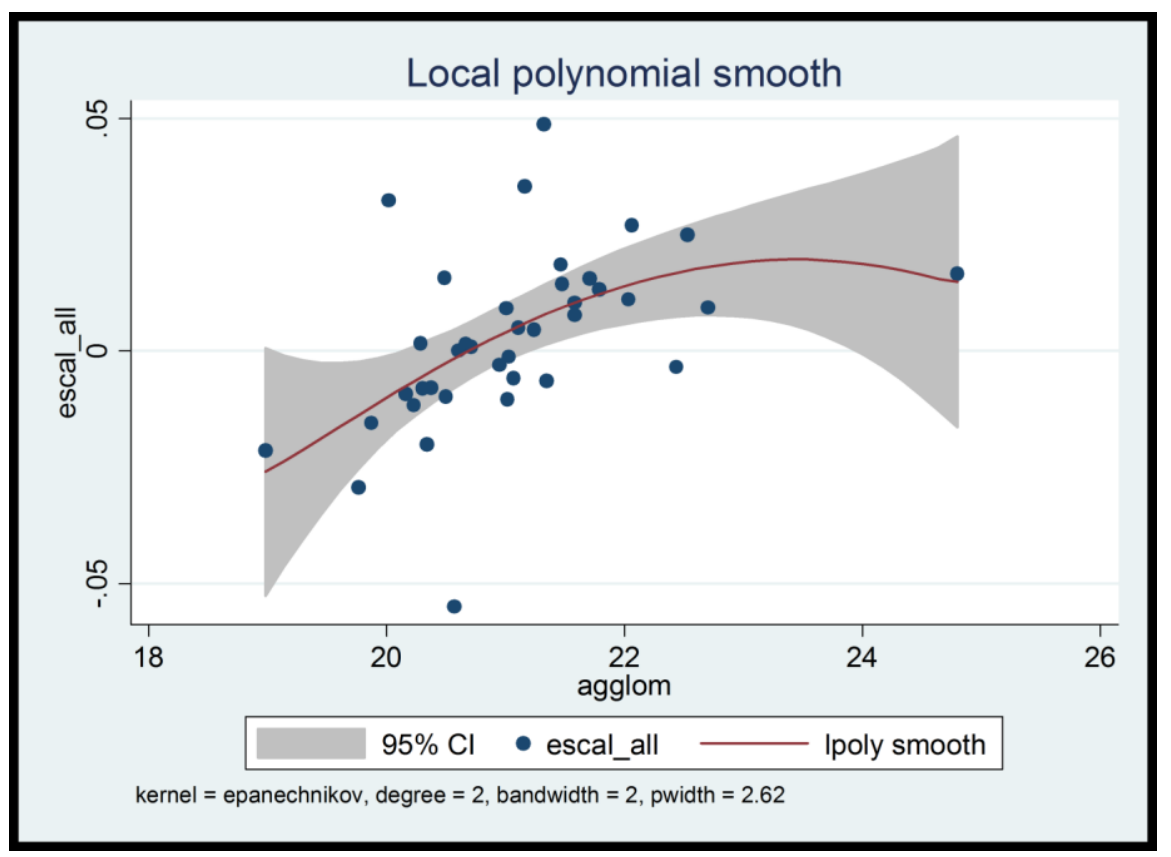


Figure A3 (a) Quantile Estimates of Agglomeration Coefficient

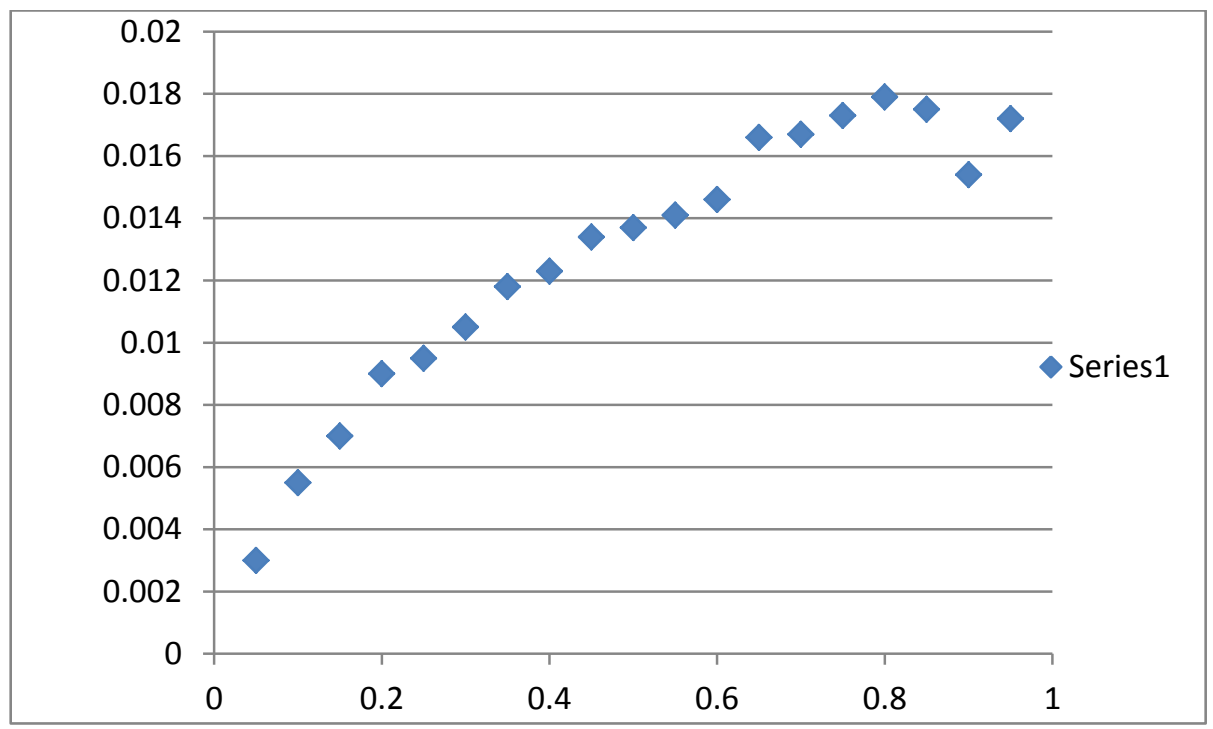

Figure A3 (b) Quantile Estimates of Unemployment Differential Effect

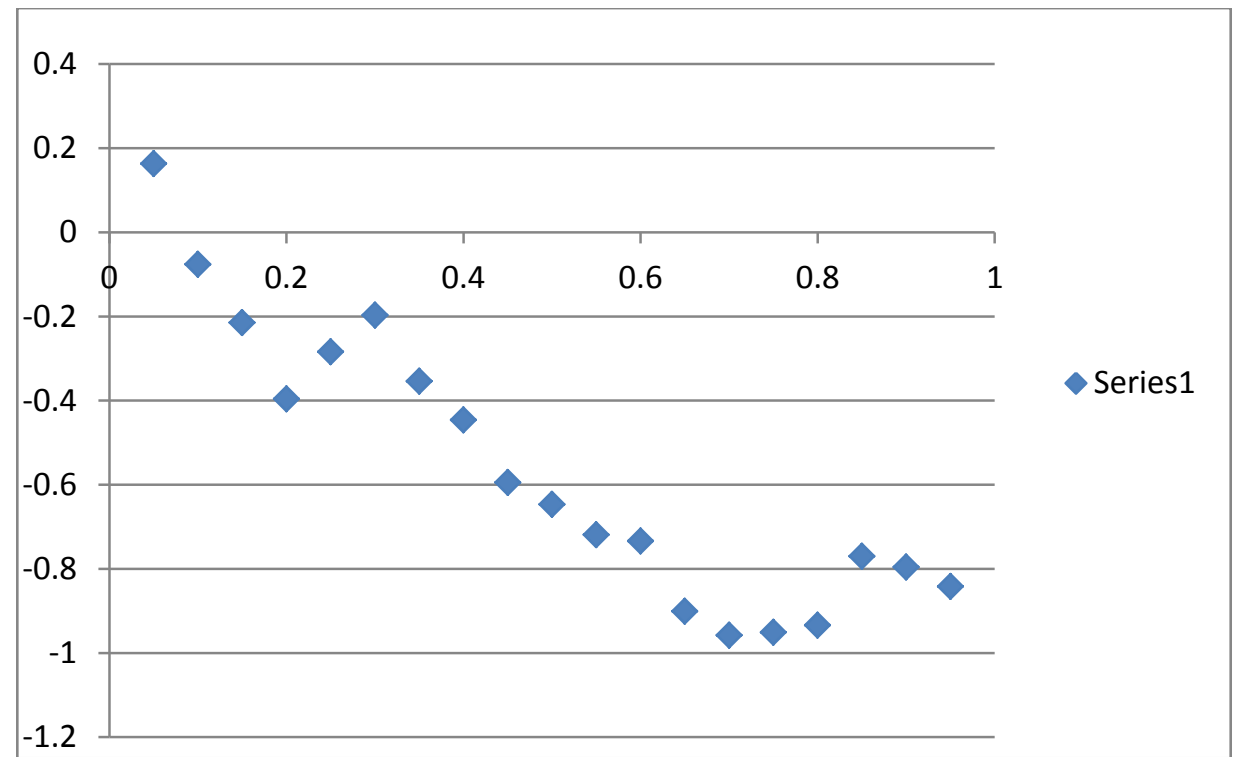




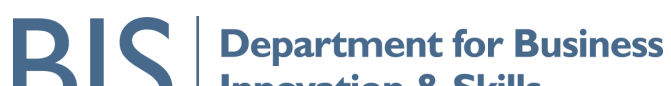 BIS}

\section{Spatial Economics Research Centre (SERC)}

London School of Economics

Houghton Street

London WC2A 2AE

Tel: 02078523565

Fax: 02079556848

Web: www.spatialeconomics.ac.uk

SERC is an independent research centre funded by the Economic and Social Research Council (ESRC), Department for Business Innovation and Skills (BIS) and the Welsh Government. 